I. FAR ULTRA-VIOLET RADIATION : THE SUN 


\title{
THE EXTREME ULTRAVIOLET EMISSION FROM THE SUN BETWEEN THE LYMAN-ALPHA LINES OF H I AND C VI
}

\author{
by R. Tousey, W. E. Austin, J. D. Purcell and K. G. Widing \\ (E. O. Hulburt Center for Space Research $\left({ }^{1}\right)$ \\ U. S. Naval Research Laboratory, Washington, D. C. 20390 U. S. A.)
}

RÉsUMt́. - Grdee aux recherches menées au moyen de spectrographes d réseaux portés par des fusées, on connaît maintenant la nature du spectre solaire dans l'extrême ultra-violet jusqu'à 33,7 A, la raie Lyman $\propto$ de $C V I$.

On a pu identifier la plupart des raies d'émission de longueur d'onde supérieure à $400 \AA$ ainsi que celles comprises entre $80 \AA$ et 33,7 $\AA$. Cependant, entre $149 \AA$ et $400 \AA$, il subsiste de nombreuses raies non identifiées. On a pu montrer que vingt au moins d'entre elles proviennent d'atomes de Fe puisqu'elles apparaissent dans les spectres de plasmas à haute température où l'on a introduit du Fer; mais on en ignore les états d'ionisation. On a aussi reconnu l'existence des raies des éléments les plus abondants dans le Soleil, $\mathrm{H}, \mathrm{He}, \mathrm{C}, \mathrm{N}, \mathrm{O}, \mathrm{Ne}, \mathrm{Mg}, \mathrm{Al}, \mathrm{Si}, \mathrm{S}$ et $\mathrm{Fe}$, dans les états d'ionisation de potentiel inférieur à $500 \mathrm{eV}$. Les exceptions les plus remarquables sont celles des séquences du fluor et du néon.

Au moyen de spectrographes à incidence normale, on a obtenu des spectrohéliogrammes qui montrent que les raies d'émission, Fe XV $284 \AA$, Fe XVI 335, $361 \AA$, sont produites principalement dans les régions actives; au contraire de He II $304 \AA$, émise avec une grande intensité sur le disque aussi. Les centres d'activité intenses émettent aussi un spectre continu dans la gamme 170-300 $\AA$.

ABSTRACT. - As a result of research carried out with rocket-borne grating spectrographs, the nature of the extreme ultraviolet spectrum of the Sun is now known to a short wavelength limit of $33.7 \AA$, the Lyman-alpha line of $C$ VI. Most of the emission lines of wavelengths greater than $400 \AA$ have been identified, as have those from $80 \AA$ to $33.7 \AA$. Between $149 \AA$ and $400 \AA$, however there are many intense emission lines whose identity has not as yet been established. Twenty or more have been proved to be from iron, since they appear in spectra obtained from high temperature plas. mas into which iron has been introduced, but the stages of ionization have not yet been established. Lines from the elements most abundant in the Sun, $\mathrm{H}, \mathrm{He}, \mathrm{C}, \mathrm{N}, \mathrm{O}, \mathrm{Ne}, \mathrm{Mg}, \mathrm{Al}, \mathrm{Si}, \mathrm{S}$ and Fe, in most of the stages of ionization requiring $500 \mathrm{eV}$ or less for production have been found. The outstanding exceptions are the lines in the fluorine and neon sequences.

Spectroheliograms, photographed with normal incidence spectrographs, show that the emission lines Fe XV $284 \AA$, Fe XVI 335, $361 \AA$, originate principally from active regions, in contrast to He II $304 \AA$, which is emitted with great intensity from the disc also. Continuum emission, in the wavelength range 170-300 $\AA$, has been recorded from intense centers of activity.

Гезюме. - Благодаря исследованиям, проведенным при посредстве многоканальных спектрографов на ракетах, теперь иввестна природа солнечного спектра в дальней ультрафиолетовой области до $33,7 \AA$, лаймановская линия $\propto \mathrm{C}$ VI. Удалось отождествить большинство эмиссионных линий с длиной волны превышающей $400 \AA$, как и с длиной волны между $80 \AA$ и $33,7 \AA$. Однако, между $149 \AA$ и $400 \AA$ многочисленные линии остались неотождествленными. Удалось показать, что по крайней мере 20 из них происходят из атомов $\mathrm{Fe}$, т. к. они появляются в спектрах плазм с высокой температурой, куда было введено железо ; но ионизационные состояния не известны. Распознано также существование линий самых обильных элементов в Солнце - $\mathrm{H}, \mathrm{He}, \mathrm{C}, \mathrm{N}, \mathrm{O}, \mathrm{Ne}, \mathrm{Mg}, \mathrm{Al}, \mathrm{Si}, \mathrm{S}$ и Fe в состояниях ионизации с потенциалом ниже 500 эв. Самыми замечательными исключениями являются ряды снимков флуора и неона.

При посредстве спектрографов с нормальным направлением падения были получены спектрогелиограммы, показывающие, что эмиссионные линии, Fe XV $284 \AA$, Fe XVI 335, 361 А, произведены главным образом в активных областях, в противоположность Не II $304 \AA$, излучаемых с большой интенсивностью также на диске. Интенсивные центры активности излучают также непрерывный спектр в диапазоне $170-300 \AA$.

(1) Sponsored jointly by the Office of Naval Research and the National Soience Foundation. 


\section{INTRODUCTION}

From the simplest beginning with $\mathrm{V}-2$ rockets in 1946, steady progress has been made in observing the extreme ultraviolet spectrum of the Sun, first by several groups in the USA, and within the last decade in the USSR. Work is now going on in various European countries, and a group in the United Kingdom has recently achieved success. During the four years that have elapsed since the first Liège symposium on the extreme ultraviolet spectra of stars, many new results have been obtained. The solar spectrum has now been recorded in very considerable detail from $3000 \AA$ to $13 \AA$ in soft X-rays, spectroheliograms have been obtained at several wavelengths, and the first monitoring experiments have been conducted from satellites. Interpretation of the observations seems now to be really under way, but the more we learn, the more we realize the need for rocket and satellite-borne experiments of greater power and sophistication. Spectroheliograms of increased spatial resolution, spectra showing still fainter lines and resolving the many blends, improved measurements of intensities, and more extensive solar monitoring are some of the goals of future experiments. As indicated by the title, the principal spectral region to be discussed is that in which the radiation arises from the chromosphere and corona. For completeness, however, a brief review of the longer wavelength rocket region is included; chromospheric radiation is present here also, although the radiation is mainly from the transition layer and the photosphere.

\section{The Photospheric and Transition Regions}

From $3000 \AA$ to $2085 \AA$ the solar spectrum is mainly photospheric, just as it is to longer wavelengths. On August 21, 1961 using an echelle spectrograph oapable of resolving $0.03 \AA$, PURCFLL, GARRETT and Tousey (1963) recorded 6,400 Fraunhofer lines between $3000 \AA$ and $2250 \AA$, and determined wavelengths to $0.01 \AA$. About half the lines have been tentatively identified by comparison with the ultraviolet multiplet tables of MOORE (1950). A re-flight of the same instrument on November 19, 1964 was successful in extending the high resolution spectrum to $2100 \AA$. It is planned to publish both a line list with identifications and an atlas showing intensity profiles. All measurements of solar intensity distribution made up to the present were reviewed by TousEY (1963).

Beginning at $2085 \AA$ the Fraunhofer lines become extremely weak and the first emission lines begin to appear above the continuum. Parts of this region, are shown in Figure 1, taken from a spectrum photographed by Tousey, Purceld, Austin, GarRetT and Widing (1964) on August 22, 1962 with a nearly stigmatic, doubledispersion, grating spectrograph resolving $0.2 \AA$. The change in character of the spectrum at $\lambda<2085 \AA$ was first recognized by JoHnson, Malitson, Purcell and Tousey (1958). As recorded on May 13, 1959 with $0.5 \AA$ resolution (Detwiler, Garrett, Purcell and TouSEY, 1962), the continuum between the Fraunhofer lines changes abruptly from $5500^{\circ} \mathrm{K}$ at $\lambda>2100 \AA$ to $5050^{\circ} \mathrm{K}$ near $2050 \AA$. Both above and below $2100 \AA$ the bottoms of the Fraunhofer lines reach $4900^{\circ} \mathrm{K}$ and a few fall even lower; for example, $\mathrm{Mg}$ I $2025.82 \AA$ reaches $4800^{\circ} \mathrm{K}$ and the autoionization pair of $\mathrm{Al}$ I $1935 \AA$ dips to $4650^{\circ} \mathrm{K}$. Absorption by the ionization continua of $\mathrm{Al}$ and $\mathrm{Ca}$ by $\mathrm{CO}$ and $\mathrm{NO}$, and by some form of hydrogen have been suggested as explanations, but there is still no theory which describes satisfactorily this strong quasi-continuous absorption and the suddenness with which it sets in.

Progressing to shorter wavelengths the continuum level falls gradually; the Fraunhofer lines all but vanish by $1690 \AA$ and none have been detected below $1530 \AA$. Emission lines begin to appear, becoming more and more profuse the shorter the wavelength. Below $1280 \AA$ the continuum level rises as the wing of $\mathrm{H} I \mathrm{Ly} \alpha$ is entered.

The number of lines that have been distinguished in the August 22, 1962 spectrum of $0.2 \AA$ resolution is approximately one per Angstrom, on the average. From $2000 \AA$ to $1700 \AA$, nearly all are Fraunhofer lines but identification is difficult because of their weakness and similarity. Many are from Fe I and Si I. From $1725 \AA$ to $1200 \AA$, almost all are emission lines; about half have been identified. In the range $1700 \AA$ to $1725 \AA$ emission and absorption lines are mixed together in approximately equal numbers.

All emission lines as yet identified in the rocket spectra are from the most abundant solar elements through $\mathrm{Fe}$ and including $\mathrm{Al}$. At $\lambda>1216 \AA$ almost all are chromospheric rather than coronal. The largest number are from $\mathrm{C} \mathrm{I}$ and Fe II. The spectrum of the former is exceedingly rich and all the multiplets listed by Moore (1950) appear to be present. The emission line of longest 
wavelength has been tentatively identified as C I 1993.65 $\AA, 2 p^{2}{ }^{1 D}-3 s{ }^{2} \mathrm{P}^{0}$. Prominent near $1650 \AA$ is $\mathrm{CI}(2)$, which contains the raie ultime $1656.998 \AA$; four of its six components are resolved in Figure 1, but there is a blend problem; a fairly intense line is present where the weakest component of the multiplet, $1657.368 \AA$, should lie.

A great many of the emission lines from $1725 \AA$ to $1550 \AA$ have been identified as Fe II, which gives rise to intense Fraunhofer lines at $\lambda>2100 \AA$. In Figure 1 multiplets (40-43 and 8$)$ are quite prominent; the two leading lines of (43), 1670.759 $\AA$, probably mask $\mathrm{Al} \mathrm{II}(2), 1670.81 \AA$, with the result that the identification of $\mathrm{Al}$ II is not certain. From $1550.26 \AA$ there is a gap in the spectrum of $\mathrm{Fe} I I$, as listed by MOoRe (1950); this seems to explain the scarcity of solar emission lines in this range. Below this gap a few Fe II lines are present, but they are faint, and none of the many Fe II lines between $1216 \AA$ and the ionization limit, $766 \AA$, have been detected.

In the range $\lambda>1200 \AA$, the lines originating highest in the chromosphere are $\mathrm{N} \mathrm{V} \mathrm{(1)} \mathrm{1238.800,}$ 1242.778 $\AA$. Amongst the unidentified lines there are certain to be others originating still higher in the chromosphere, or in the corona. For example, the line at $1241.9 \AA$ is coronal because of its extension beyond the Sun's limb, which was especially noticeable when the Sun was active (Detwiler, Purcell and Tousey, 1961).

A number of observations connected with centerto-limb intensity changes can be made from the August 22, 1962 spectrum. Near $1650 \AA$ this spectrum was closely stigmatic, but on either side the correction became less complete. At the extremes, $1200 \AA$ and $2000 \AA$, there was approximately 1 minute of uncorrected astigmatism. Taking this into consideration, the continuum from $2000 \AA$ to $1530 \AA$ as seen between the lines, "shows no change in intensity to within 20 seconds of the limb, which is the approximate limit set by the instrumental resolution. This is the type of behavior that would be expected for radiation which originates from the transition layer, where the temperature passes through a shallow minimum with increasing altitude. The fact that Fraunhofer lines are present and faint from $2085 \AA$ to $1700 \AA$, indicates that a substantial fraction of the radiation in this spectral region originates from just below the temperature minimum.

Below $1530 \AA$ the character of the continuum is different. Here it shows conspicuous limb brightening much like that seen in many of the emission lines. This continuum is attributed to radiation from the ionization continuum of $\mathrm{Si}$ I since the wavelength at which it appears is exactly right. The enhancement at the limb, and the absence of Fraunhofer lines show that the radiation arises from the outer edge of the transition layer where the temperature is beginning to rise as the chromosphere is entered. All the way to shorter wavelengths, the continuum exhibits limb brightening to a greater or less extent. This is also true of the wings of Iyman-alpha and would be expected, since the Lyman-alpha wing-radiation originates low in the chromosphere. In Figure 1, although a diaphragm cut across the upper part of Lyman-alpha and a speck of dirt in the slit cast a diagonal shadow at the lower edge, the limb effect can still be seen.

The intensity level of the continuum in this spectral range is, of course, connected quite directly with the temperature between the photosphere and the chromosphere. The value of the radiation temperature between $1750 \AA$ and $1850 \AA$ was determined in 1959 to vary between 4625 and $4700^{\circ} \mathrm{K}$; from $1300 \AA$ to $1500 \AA$ the value was 4700 to $4750 \circ \mathrm{K}$ in 1960 . In both these years the Sun was active. These values are averages taken across the transition region and are not the minimum value reached by the temperature curve. De JAGER (1963) has taken this into account and shown that a $4700^{\circ} \mathrm{K}$ temperature near $1500 \AA$ is compatible with a solar model with a flat minimum at approximately $4500^{\circ} \mathrm{K}$. Thus the rocket results support this value of minimum temperature in the Sun's transition region.

Nearly all of the emission lines show limb brightening, as would be expected since they originate in the chromosphere. The degree of limb brightening depends on the particular line and is generally greater, the higher the temperature required to produce the particular ionic species. For example, the lines of C I show the least limb brightening; in fact, some of them appear to show hardly any change at the limb. All the lines of Fe II become brightened toward the limb, and H-alpha of He II $1640.47 \AA$ is conspicuously brightened and broadened at the limb. In the range $\lambda>1200 \AA$, the lines showing the most limb brightening are C IV near 1550 and N V near $1240 \AA$.

The interpretation of the center-to-limb variation in the extreme ultraviolet spectra is compli- 
cated by effects produced by active regions. Spectra photographed in 1959 and 1960 when the Sun was active, showed that plage regions produce enhanced emission in the continuum from $1530 \AA$, the longest wavelength then photographed with a stigmatic spectrograph, to shorter wavelengths, and also, of course, in the emission lines (Detwiler, Purcell and Tousey, 1961). On August 22, 1962 however, the Sun was so quiet that almost no plage regions were present. There is some evidence, however, in the silicon continuum near the limb, and also in the emission lines, that part of the enhancement, especially at the upper edge of the spectrum shown in Figure 1, must be presumed to arise from an active region near the limb which happened to fall on the slit. However in CaK spectroheliograms photographed during this period no plage regions appeared to be present at the part of the limb covered by the slit. The further elucidation of these matters must await new photographs of the solar spectrum,

\section{The Normal Incidence Range, LYMAN-ALPHA TO $500 \AA$}

The wavelength range from $1200 \AA$ to $500 \AA$ is best photographed with grating spectrographs of the normal-incidence double-dispersion type. Although photographic spectra obtained with grazing-incidence spectrographs extend into this wavelength region, they are less valuable because of the presence of many intense higher order lines and because they are highly astigmatic.

Double-dispersion spectra having about $1 \AA$ resolution were obtained on April 19, 1960 by Detwiler, Purcell and Tousey (1961). A spectrum with much higher resolution was obtained on August 22, 1962 by Tousey, Purcell, AusTIN, GARRETT and WIDING (1964) using a grating having 2400 instead of 600 lines $/ \mathrm{mm}$. The principal portion is reproduced in Figure 2. The intensities of the lines are less than in the earlier spectrum, partly because of the reduced activity of the Sun. The continuum and wing of $\mathrm{HI} \mathrm{Ly} \alpha$ are much weaker than in the 1960 spectrum because a narrow slit was used. This was done in order to obtain the greatest possible resolution and a value of $0.07 \AA$ was attained.

The emission lines present in this wavelength range are similar to those at longer wavelengths ; a few are coronal but most are chromospheric. Some lines of C I, whose ionization limit lies at $1100 \AA$ contribute to the faint features in Figure 2.
C I (10) through (30) are all present, but not all components of these multiplets are resolved and some are masked by blends. All of these lines are characterized by relatively little change in intensity across the disc.

By far the greatest number of emission lines in this spectral range, and also to still shorter wavelengths, are produced by screening type transitions, that is, transitions in which the principal quantum number does not change. This is true of C II-IV, N I-V, O II-V, Si III and IV, and S II-V. For example, in C II nearly all the screening transitions listed by Moore (1950) have been found, but no others. These are C II (1) 1335.684, 1334.515 $\AA$, C II, 1037.017, 1036.330 $\AA$, the latter masking the strongest expected line of Be II, 1036.271 $\AA$; C II (3), four lines near $904 \AA$; which are present but unresolved; and C II (7), three lines near $1010 \AA$, present unresolved in 1960 , but too faint to detect in Figure 2. Similarly in C III, the resonance transition, C III (1) $977.026 \AA$, is very strong, as are the six components of C II (4) near $1175 \AA$, five of which are resolved in Figure 2. C III (2), 386.203 $\AA$ and C III (3), 310.171 $\AA$, transitions where the principal quantum number changes from 3 to 2 and 4 to 2 , respectively, have not been found with grazing-incidence instruments. The earlier report of these lines by VIOLETT and Rense (1959) has not been confirmed by later observations." Likewise with C IV, only the screening transitions multiplet (1), 1548.195, 1550.768 $\AA$, are present. The next strongest multiplet in the laboratory, C IV (2), 312.412, $312.455 \AA$, a transition where the principal quantum number changes from 3 to 2 , is masked. ZIRIN and DIETz (1963) have made use of the relative intensities of such lines to calculate temperatures in the chromosphere.

The lines of nitrogen are not as strong as those of carbon or silicon. This is unexpected from its abundance in the Sun, 7.98 compared to 8.72 and 7.50 for $\mathrm{C}$ and $\mathrm{Si}$, respectively (GoLdBerg, Müller, and Aller, 1959). From N I, multiplet (1) can be seen in Figure 2 at $1199.550,1200.218,1200.707 \AA$, the transition $2 p^{3}{ }^{4} \mathrm{~S}^{0}-3 s{ }^{4} \mathrm{P}$. However, N I (2), 1134.979, $1134.417,1134.168 \AA$, the screening transition $2 p^{3}{ }^{4} \mathrm{~S}^{0}-2 p^{4}{ }^{4} \mathrm{P}$, is stronger than $\mathrm{N} \mathrm{I}(1)$, although in Figure 2 it appears to be weaker, because of the rapid decrease in speed of the spectrograph in this region. In N II, only multiplet (1) near $1085 \AA 2,2 p^{3}{ }^{3} \mathrm{P}-2 p^{3}{ }^{3} \mathrm{D}^{0}$ has been detected. There is however, an extra line in the 
midst of the three components that are resolved, $\mathrm{H}_{\gamma}$ of $\mathrm{He} \mathrm{II}, 1084.97 \AA$; it is distinguished from the N II lines by its greater intensity variation from center to limb. $\mathrm{H} \alpha$ of $\mathrm{He}$ II is lost, of course, by blending with H I Ly $\alpha$. N III (1), $2 p^{2} \mathrm{P}^{0}-2 p^{2}{ }^{2} \mathrm{D}$ is present in Figure 2 with two of its components blended at $991.58 \AA$ and the third clearly resolved at $989.790 \AA$. N IV (1), $2 s^{2}{ }^{1} \mathrm{~S}-2 p{ }^{1} \mathrm{P}^{0}, 765.14 \AA$ was present as a faint line in the 1960 spectrum. Although N V (1), $1230.800,1242.778 \AA$, is strong, the lines in the short wavelength range near $200 \AA$, produced by transitions in which the total quantum number changes, have not been distinguished.

In the case of $O \mathrm{I}$, the spectrum in the extreme ultraviolet does not arise from screening type transitions. The strongest lines are multiplet (2) $1302.174,1304.858,1306.023 \AA, 2 p^{4}{ }^{3} \mathrm{P}-3 s^{3} \mathrm{~S}^{0}$. All the other multiplets listed by Moore (1950) are present, although certain lines are extremely faint. O I (4) is of particular interest because its leading line, 1025.766 $\AA$, is nearly coincident with H I Ly $\beta$; therefore, absorption by atmospheric hydrogen and oxygen may affect this line as well as Lyß. The second member of O I (4), 1027.42 $\AA$, is present in Figure 2 and the third and weakest member $1028.15 \AA$, is barely detectible. These two latter lines, having laboratory intensities, 8 and 7 , respectively, should be stronger than the singlet system line O I (6), $2 p^{4}{ }^{1} \mathrm{D}-3 s^{\prime}{ }^{1} \mathrm{D}^{0}$, at $1152.129 \AA$. However, the latter is very strong in the spectrum of Figure 1 and is one of the narrowest recorded, with width equal to the slit width, $0.07 \AA$. Its intensity is much greater than the lines of $\mathrm{OI}(4)$, even making allowance for the changing speed of the spectrograph between $1152 \AA$ and $1027 \AA$; this may, in part, be explained by atmospheric absorption by $\mathrm{O}$, which is strong for O I (4) but negligible for O I (7). A weaker line in the singlet system, O I (7), $2 p^{4}{ }^{1} \mathrm{D}-3 s^{\prime \prime}{ }^{1} \mathrm{P}^{0}, 999.493 \AA$, is present in the 1960 spectrum, but not in the 1962 . A third line, O I (8), $2 p^{4}{ }^{1} \mathrm{D}-3 d^{\prime}{ }^{1} \mathrm{~F}^{0}, 922.011 \AA$, can possibly be distinguished in Figure 1 between $\mathrm{H} I \mathrm{Ly} \theta$ and Lyı. O I (9) $2 p^{4} 1 \mathrm{~S}-3 s^{\prime \prime}{ }^{1} \mathrm{P}^{0}$, 1217.643 $\AA$ is present in the long wavelength wing of Lyman-alpha; it is not the line which shows in Figure 2, but can be seen in less heavily exposed spectra.

For O II-IV, however, only screening transitions have been detected. O II (1) and O III (1) are present in the August 1962 spectrum. Their members are nearly coincident at $835 \AA$ but the leading lines are resolved. O III is a little stron- ger than $\mathrm{O}$ II. The screening transitions $\mathrm{O}$ II (4), $718.484,718.562 \AA$ and $O$ III (2), four lines near $703 \AA$, are present in the photoelectrically scanned spectrum of HaLL, DaMON, and HINTEREGGER (1963), as is 0 II (3), three lines near $508 \AA, O$ III (7) $599.6 \AA$ and O III (8) $525.8 \AA$. O IV (1) three lines near $790 \AA$ are present, and in the photoelectric spectrum, O IV (3), four lines near $555 \AA$, are strong. $\mathrm{OV}(1), 2 s^{2}{ }^{1} \mathrm{~S}-2 p{ }^{1} \mathrm{P}^{0}$, $629.732 \AA$ is intense but $\mathrm{OV}$ (2) $2 s^{2}{ }^{1 \mathrm{~S}}-3 p{ }^{1} \mathrm{P}^{2}$ $172.68 \AA$ is present, although relatively faint. Finally $\mathrm{O}$ VI (1) $2 s^{2} \mathrm{~S}-2 p{ }^{2} \mathrm{P}^{0}, \quad 1031.912$, $1037.613 \AA$ are extremely intense relative to O VI (4), $2 p{ }^{2} \mathrm{P}^{0}-3 d^{2} \mathrm{D}, 173.082,172.935 \AA$, which are present in spite of the fact that in the laboratory the intensities of the latter, 13, 12 are greater than those of the former, 10, 9 .

The Lyman series of hydrogen, as shown in Figure 2, is of interest because of the resolution, which is much greater than was attained in 1960 . Both $\mathrm{Ly} \alpha$ and Ly $\beta$ are strongly self-reversed. Ly $\alpha$ is, of course, greatly overexposed, but the self-reversal can be seen in the two ghosts, which appear below the principal spectrum because of the double-dispersion. The contour of these lines has been discussed by Tousey, Purcell, Austin, GaRRETT, and Widing (1964). The resolution is not sufficient to distinguish a telluric absorption core, such as was found by Purcell and TouSEY (1960). The peak-to-peak separation in Ly $\beta$ is approximately two-thirds as great as for Ly $\alpha$, and this is also true of the half-maximum width of the emission line as a whole. The central reversal however, after correction for absorption effects by oxygen and hydrogen in the earth's atmosphere, appears to be nearly as deep for Ly $\beta$ as for Ly $\alpha$. Close to the limb the peak-topeak separation increases slightly for $L y \beta$, just as it does for $L y \alpha$. The reduced width of $L y \beta$ is explained satisfactorily as partly produced by the ratio of wavelengths, and partly by the lower $f$-value for Ly $\beta$ and its effect on the optical depth. As yet, the depth of the self-reversal of $\operatorname{Ly} \beta$ has not been reproduced by a calculation of the type made for Lya by MorTon and Widing (1960), using the theory of JEFFERIES and Thomas (1959, 1960 ) and a three-level atom.

The higher members of the Lyman series through Ly $\lambda, 918.13 \AA$, are present in Figure 2, and are followed by a vestige of the Lyman continuum. These lines do not seem to show self-reversal, but it is not possible to be certain of this, because of their faintness. Their widths appear to be about $0.3 \AA$. They are clearly broad, by comparison 
to S VI, 933.38 $\AA$. In C III, $977.026 \AA$, the broadening was produced by overexposure.

Just as in spectra obtained from earlier flights the intensity of Ly $\gamma$ was greatly reduced because, of absorption by $\mathrm{N}_{2}$. This was discussed by Detwiler, Garrett, Purcell, and TouSEY (1961). It was shown that Ly $\gamma, 972.54 \AA$, is nearly coincident with an absorption band of atmospheric $\mathrm{N}_{2}$. The bandhead lies at $972.2 \AA$ and the maximum absorption coefficient is reached at about $972.5 \AA$ (WoRLEY, 1943). In Figure 2 it can be seen that Ly $\gamma$, photographed over the peak altitude of $233 \mathrm{~km}$, shows a strong and rather sharp long wavelength edge. This is produced by the sudden attenuation by $\mathrm{N}_{2}$. As a result, it is not possible to say whether $\mathrm{Ly}_{\gamma}$ is selfreversed in the Sun. Recently, OGAWA and CAIRNS (1964) have photographed Ly $\gamma$ with a 3M grating spectrograph, and shown that $\mathrm{N}_{2}$, introduced into the spectrograph at a pressure of $2 \times 10^{-4} \mathrm{~mm} \mathrm{Hg}$, absorbs all of Ly $\gamma$ except a faint residual, which is displaced to about 972.56 $\AA$. In Figure 2, the most intense part of solar Ly $\gamma$ is also displaced longward by about $0.025 \AA$. The absorption is less, however, since some of the short wavelength part of the line is present.

Higher members of the Balmer series of $\mathrm{He}$ II have been searched for ; $\mathrm{H} \gamma, 1084.97 \AA$, is present, as was mentioned. $\mathrm{H} \delta$ is lost in $\mathrm{H} I \operatorname{Ly} \beta . \mathrm{H} \varepsilon$, 992.39 $\AA$, may be present, but the faint line near this wavelength looks broad, by comparison to $\mathrm{H}_{\gamma}$, suggesting blending. $\mathrm{H} \zeta, 972.14 \AA$, might be expected just at the short wavelength edge of $\mathrm{H} \mathrm{I} \mathrm{Ly} \gamma$ but is not present.

\section{The Grazing-Incidence Region, $500 \AA$ Tо $33 \AA$}

The region to short wavelengths of $500 \AA$ is best studied with grazing-incidence spectrographs, which take advantage of the extremely high reflectance of all materials at angles of incidence approaching $90^{\circ}$. Using an instrument of this type, Rense (1953) obtained the first photograph of the Lyman-alpha line of hydrogen, and VIoLETT and RENSE (1959) discovered the Lymanalpha line of $\mathrm{He}$ II, 303.78 $\AA$. Although the grazing-incidence spectrograph is far more efficient at short wavelengths than the normalincidence, the stray light associated with the longer wavelength portion of the solar spectrum is so intense that it swamps all but the strongest solar emission lines below $500 \AA$. Because of this, and also certain difficulties with the photographic film, the spectra obtained by VIOLETT and RENSE (1959) were difficult to interpret; only a few of the lines reported by them have been confirmed by later work.

The stray light problem was solved to a large extent by Austin, Purcell, and Tousey (1962), who introduced at a position just in front of the entrance slit a filter consisting of an unbacked aluminium foil, $1000 \AA$ in thickness. The transmittance of such a filter is zero at $\lambda>837 \AA$, rises gradually to a maximum value of $70 \%$ at $170 \AA$, the $\mathrm{L}_{2 \cdot 3} \mathrm{X}$-ray edge and falls to $8 \%$ at $150 \AA$. The filter is quite opaque from $148 \AA$ to $80 \AA$, but transmits again to shorter wavelengths.

With a spectrograph using a 600-line $/ \mathrm{mm}$, $40 \mathrm{~cm}$ radius grating at $5^{\circ}$ from grazing incidence, equipped with this filter, the solar spectrum was photographed on June 21, 1961 and again on August 22, 1962 to a short wavelength limit of $171 \AA$. On May 10, 1963, using the same instrument but with improved focus and a narrower slit, spectra were photographed to approximately $40 \AA$. On September 20, 1963 a similar instrument with a 2400 -line $/ \mathrm{mm}$ grating was flown; the range $188 \AA$ to $33 \AA$ was covered with increased resolving power (TousEY, 1964).

The portion of the spectrum obtained on May 10,1963 from $148 \AA$ to $500 \AA$ is shown in Figure 3. The resolution is approximately $0.6 \AA$ and wavelengths have been determined to $0.1-0.05 \AA$, the accuracy depending on the particular line. The print has been prepared to show the faintest lines, hence strong lines are overexposed and broadened, for example, He II, $303.8 \AA$ and the line at $171.1 \AA$; breaks that appear near $165 \AA, 215 \AA$ and $425 \AA$ are not real but were caused by piecing together different prints.

This range has also been covered with photoelectrically scanned grazing-incidence monochromators, in which the stray light problem is avoided by the use of a metallic photocathode such as tungsten, whose long wavelength response limit lies at approximately $1300 \AA$. Generally the photographic spectra give the most accurate wavelengths and highest resolution. The photoelectrically scanned spectra of HINTEREGGER and colleagues, (cf., HinteregGer, HALL, and SchweIzer, 1964) provide the most accurate intensity data and have only slightly less resolution than the photographic spectra. They fill in the region between $148 \AA$ and $80 \AA$ which has 
not yet been covered photographically. Photoelectrically scanned spectra were obtained by Behring, NeuYert, and Lindsay (1962) from OSO-I, the first orbiting solar observatory of the National Aeronautics and Space Administration (NASA). The wavelength range covered was $170 \AA$ to $400 \AA$, with a resolution of about $1 \AA$. These spectra give data on the changes that take place in the solar spectrum from day to day and show dramatically how the various emission lines change intensity with solar conditions.

In Figure 4, the photographic spectra obtained by the Naval Research Laboratory (NRL) are compared with the photoelectrically scanned spectrum of HiNTEREGGer, HaLL, and SchweIZER (1964) over the range $148 \AA$ to $182 \AA$. The September 20, 1963 spectrum permitted the determination of wavelengths with an accuracy of $0.1 \AA$ to $0.02 \AA$, depending on the nature of the particular line; the resolution was approximately $0.15 \AA$. The photoelectrically scanned spectrum agrees remarkably well with the photographic spectra for lines above a certain intensity level, and in places nearly as much detail is resolved as in the September 20 spectrum, However, the agreement begins to deteriorate below approximately 200 counts/ second, and below 100 counts/second the agreement is not at all good. This is true with respect to the low-level details only; the average level is still a good measure of the flux that is present.

The range $148 \AA$ to $80 \AA$, as observed by HinteREGGER, HALL, and SchwEITZER (1964), is shown in Figure 5. This is apparently a region where all of the solar emission lines are weak. Few peaks rise above the 200-count/second level. Therefore, the significance of much of the fine structure that is present in this trace is open to question and must be confirmed by further work.

The soft X-ray end of the solar spectrum, as photographed by NRL, is shown in Figure 6 In the first spectrum the intensities of the emission lines were apparently considerably greater than in the second, however, the resolution was much less because of the use of the $600-\mathrm{line} / \mathrm{mm}$ grating. From the September 20, 1963 spectrum in this region, wavelengths have been determined to $0.02 \AA$ and lines as close as 0.18 were well resolved. Although the film extended to much shorter wavelengths, no lines shortward of $33.7 \AA$ were recorded with certainty, This is attributed to the fact that the grazing angle was $5^{\circ}$. By reducing the angle to $2^{\circ}$ it is probable that lines at shorter wavelengths could be recorded. From the work of Blake, Chubb, Friedman, and UNZICKER (1964), reported by CHUBB in a later paper at this symposium, it is known that emission lines are present in the range $24.8 \AA$ to $13.7 \AA$. Using a Bragg crystal spectrometer and photoelectric detection they discovered fourteen lines within these limits on July 25, 1963.

In studying the spectra reproduced in Figures 3 through 6, the presence of second and third order lines must be kept in mind. In Figure 3 at $\lambda<342 \AA$ all lines are first order, because the spectrum at $\lambda<171.1 \AA$ was greatly weakened by the aluminium filter. From $342 \AA$ to $500 \AA$, however, a large number of the lines are the second orders of the lines occurring between $171.1 \AA$ and $250 \AA$. In the photographic spectra of Figure 4 no lines other than first order have been detected, and this is believed to be true of the photoelectric spectrum also. Although the range $80 \AA$ to $148 \AA$ was covered in the photographic experiments, only second and third order lines were recorded because of the opacity of the aluminum filter. However, these second order lines were not found in the photoelectric spectrum reproduced in Figure 5. It seems probable, therefore, that this photoelectric spectrum is mainly first order, owing to the characteristic of the grating that was used. In Figure 6, second order lines begin to appear longward of $67.4 \AA$, the second order image of C VI, 33.7 $\AA$. It is possible that second order lines are present shortward of $67.4 \AA$; the second orders of $\lambda<33.7 \AA$, including those reported by BLAKE, CHUBB, FrIEDMAN, and UNzICKER (1964) might be expected. None are present, except, possibly, O VII, $21.6 \AA$.

In Table I there are listed those lines in the photographic spectra which have been identified with reasonable certainty. Rough estimates of intensity are presented on a visual scale, but are not corrected for effects associated with the changing speed of the spectrograph as a function of wavelength. An estimate of the wavelength accuracy is given $(\Delta \lambda)$. Some of the identifications have been suggested by ZIRIN (1964), but his line list, taken from the spectrum of HINTEregger, HaLL, and Schweizer (1964), is not in good agreement with Table I.

The identification problem in the grazing incidence range is a difficult one for wavelengths greater than $150 \AA$; on the other hand, from $80 \AA$ to $33 \AA$, most of the lines have been identified with a reasonable degree of confidence. The largest group of lines concerning whose identity 


\section{TABLE I}

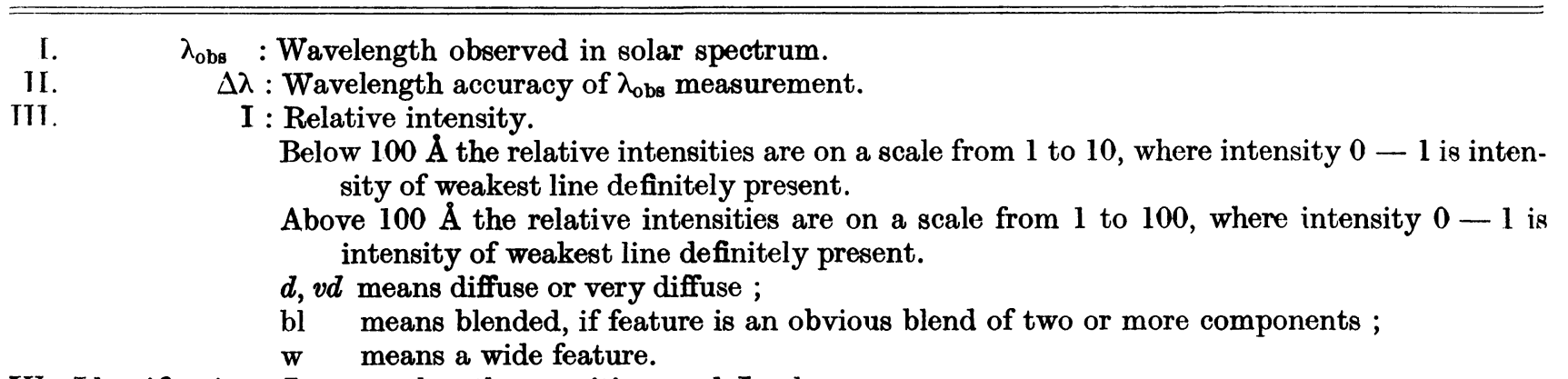

IV. Identification : Ion, wavelength, transition, and J-values ;

[ ] A wavelength listed in brackets means wavelength was obtained by a short reliable extrapolation.

( ) An ion listed in parenthesis means that the identified ion is a probable contributor to blend or feature.

\begin{tabular}{|c|c|c|c|c|c|c|}
\hline$\lambda_{\text {obs }}$ & $\Delta \lambda$ & $\mathbf{I}$ & & & IDENTIFICATION & \\
\hline$\overline{33.43}$ & $\overline{.05}$ & $0-1$ & $\mathrm{C} \mathrm{V}$ & 33.43 & $1 s^{2}{ }^{1} \mathrm{~S}-\overline{1 s 4} p^{1 \mathrm{P}^{0}}$ & $0-1$ \\
\hline 33.75 & .03 & 10 & C VI & 33.74 & $1 s^{2} \mathrm{~S}-2 p^{2} \mathrm{P}^{0}$ & $1 / 2-1 / 2,3 / 2$ \\
\hline 34.97 & .05 & $0-1$ & $\mathrm{C} \mathrm{V}$ & 34.97 & $1 s^{2}{ }^{1} \mathrm{~S}-1 s 3 p^{1} \mathrm{P}^{0}$ & $0-1$ \\
\hline 40.26 & .03 & 4 & C V & 40.27 & $1 s^{2}{ }^{1} \mathrm{~S}-1 s 2 p^{1} \mathrm{P}^{0}$ & $0-1$ \\
\hline 40.72 & .05 & 1 & $\mathrm{C} \mathrm{V}$ & 40.73 & $1 s^{2}{ }^{1} \mathrm{~S}-1 s 2 p^{3} \mathrm{P}^{0}$ & $0-1$ \\
\hline 40.92 & .05 & 1 & Si XII & $\begin{array}{l}{[40.91]} \\
{[40.95]}\end{array}$ & $2 s{ }^{2} \mathrm{~S}-3 p^{2} \mathrm{P}^{0}$ & $\begin{array}{l}1 / 2-3 / 2 \\
1 / 2-1 / 2\end{array}$ \\
\hline 42.54 & .05 & $1 d$ & $\mathrm{~S} \mathrm{X}$ & $\begin{array}{l}{[42.51]} \\
{[42.54]} \\
{[42.58]}\end{array}$ & $2 s^{2} 2 p^{3}{ }^{4} \mathrm{~S}^{0}-2 s^{2} 2 p^{2} 3 d^{4} \mathrm{P}$ & $\begin{array}{l}3 / 2-1 / 2 \\
3 / 2-3 / 2 \\
3 / 2-5 / 2\end{array}$ \\
\hline 43.18 & .05 & $0-1$ & O VII & $21.60 \times 2$ & $1 s^{2}{ }^{1} \mathrm{~S}-1 s 2 p^{1} \mathrm{P}^{0}$ & $0-1$ \\
\hline 43.75 & .03 & 3 & Si XI & 43.76 & $2 s^{2}{ }^{1} \mathrm{~S}-2 s 3 p^{1} \mathrm{P}^{0}$ & $0-1$ \\
\hline 44.18 & .03 & $4 \mathrm{bl}$ & Si IX & $\begin{array}{l}44.22 \\
44.25\end{array}$ & $2 s^{2} 2 p^{2}{ }^{3} \mathrm{P}-2 s^{2} 2 p 4 d^{3} \mathrm{D}^{0}$ & $\begin{array}{l}1-2 \\
2-3\end{array}$ \\
\hline & & & Si XII & $\begin{array}{l}44.02 \\
44.16\end{array}$ & $2 p^{2} \mathrm{P}^{0}-3 d^{2} \mathrm{D}$ & $\begin{array}{r}1 / 2-3 / 2 \\
3 / 2-5 / 2\end{array}$ \\
\hline & & & $(\mathrm{Mg} X)$ & 44.05 & $2 s{ }^{2} \mathrm{~S}-4 p^{2} \mathrm{P} 0$ & $1 / 2-1 / 2,3 / 2$ \\
\hline 45.66 & .05 & $0-1$ & $\mathrm{Si} \mathrm{XII}$ & 45.66 & $2 p^{2} \mathrm{P}^{0}-3 s{ }^{2} \mathrm{~S}$ & $3 / 2-1 / 2$ \\
\hline 46.32 & .05 & $2 \mathrm{bl}$ & Si XI & $\begin{array}{l}46.26 \\
46.30 \\
46.40\end{array}$ & $2 s 2 p^{3} \mathrm{P}^{0}-2 s 3 d^{3} \mathrm{D}$ & $\begin{array}{l}0-1 \\
1-2 \\
2-3\end{array}$ \\
\hline 47.60 & .10 & $2 \mathrm{dwbl}$ & $\begin{array}{l}\text { Si XI } \\
\text { S X }\end{array}$ & $\begin{array}{l}47.61 \\
47.65 \\
47.65 \\
47.79\end{array}$ & $\begin{array}{l}2 p^{2}{ }^{3} \mathrm{P}-2 p 3 d^{3} \mathrm{D}^{0} \\
2 s^{2} 2 p^{3}{ }^{4} \mathrm{~S}^{0}-2 s^{2} 2 p^{4} 3 s^{4} \mathrm{P}\end{array}$ & $\begin{array}{l}1,0-2,1 \\
2-3 \\
3 / 2-5 / 2 \\
3 / 2-3 / 2\end{array}$ \\
\hline 49.23 & .03 & 5 & Si XI & $\begin{array}{l}49.22 \\
49.26\end{array}$ & $\begin{array}{l}2 s 2 p^{1} \mathrm{P}^{0}-2 s 3 d^{1} \mathrm{D} \\
2 p^{2}{ }^{1} \mathrm{D}-2 p 3 d^{1} \mathrm{D}^{0}\end{array}$ & $\begin{array}{l}1-2 \\
2-2\end{array}$ \\
\hline 49.67 & .05 & $0-1$ & Si $\mathrm{X}$ & 49.70 & $2 s 2 p^{2}{ }^{2} \mathrm{D}-2 s 2 p 3 d^{2} \mathrm{~F}^{0}$ & $3 / 2,5 / 2-5 / 2,7 / 2$ \\
\hline 50.33 & .05 & $0-1$ & Fe XVI & 50.35 & $3 s^{2} \mathrm{~S}-4 p^{2} \mathrm{P}^{0}$ & $1 / 2-3 / 2$ \\
\hline 50.52 & .03 & 7 & $\begin{array}{l}\text { Si X } \\
\text { (Fe XVI) }\end{array}$ & $\begin{array}{l}50.52 \\
50.56\end{array}$ & $\begin{array}{l}2 s^{2} 2 p^{2} \mathrm{P}^{0}-2 s^{2} 3 d^{2} \mathrm{D} \\
3 s^{2} \mathrm{~S}-4 p^{2} \mathrm{P}^{0}\end{array}$ & $\begin{array}{l}1 / 2-3 / 2 \\
1 / 2-1 / 2\end{array}$ \\
\hline 50.70 & .03 & 7 & Si X & 50.69 & $2 s^{2} 2 p^{2} \mathrm{P}^{0}-2 s^{2} 3 d^{2} \mathrm{D}$ & $3 / 2-5 / 2$ \\
\hline 52.09 & .10 & $0-1 d$ & Si X & $\begin{array}{l}52.07 \\
52.16\end{array}$ & $2 s 2 p^{2}{ }^{2} \mathrm{P}-2 s 2 p 3 d^{2} \mathrm{D}^{0}$ & $\begin{array}{l}1 / 2-3 / 2 \\
3 / 2-5 / 2\end{array}$ \\
\hline 52.33 & .05 & 1 & Si XI & {$[52.30]$} & $2 s 2 p^{1} \mathrm{P}^{0}-2 s 3 s^{1} \mathrm{~S}$ & $1-0$ \\
\hline 52.49 & .10 & $0-1 d$ & Si X & 52.49 & $2 s 2 p^{2} \mathrm{D}-2 s 2 p 3 d^{2} \mathrm{~F}^{0}$ & $5 / 2-7 / 2$ \\
\hline 52.83 & .10 & $1 d$ & Si IX & $\begin{array}{l}52.81 \\
52.84\end{array}$ & $2 s^{2} 2 p^{2}{ }^{3} \mathrm{P}-2 s 2 p^{2} 3 p^{3} \mathrm{D}^{0}$ & $\begin{array}{l}1-2 \\
2-3\end{array}$ \\
\hline
\end{tabular}


TABLE I (cont)

\begin{tabular}{|c|c|c|c|c|c|c|}
\hline$\lambda_{\text {ots }}$ & $\Delta \lambda$ & I & \multicolumn{4}{|c|}{ IDENTIFICATION } \\
\hline- & - & 一 & & & & \\
\hline \multirow[t]{2}{*}{54.16} & .05 & $2 \mathrm{bl}$ & Fe XVI & 54.14 & $3 p^{2} \mathrm{P}^{0}-4 d^{2} \mathrm{D}$ & $1 / 2-3 / 2$ \\
\hline & & & (S IX) & 54.18 & $2 s^{2} 2 p^{4}{ }^{3} \mathrm{P}-3 s^{2} 3 p^{3} 3 s^{3} \mathrm{D}^{0}$ & $2-2,3$ \\
\hline \multirow[t]{3}{*}{54.56} & .10 & $1 \mathrm{dbl}$ & Si X & 54.52 & $2 s 2 p^{2}{ }^{4} \mathrm{P}-2 s 2 p 3 s{ }^{4} \mathrm{P}^{0}$ & $1 / 2-3 / 2$ \\
\hline & & & & 54.57 & & $5 / 2-5 / 2$ \\
\hline & & & & 54.60 & & $1 / 2,3 / 2-1 / 2,3 / 2$ \\
\hline \multirow[t]{2}{*}{54.75} & .10 & $0-1$ & Fe XVI & 54.73 & $3 p^{2} \mathrm{P}^{0}-4 d^{2} \mathrm{D}$ & $3 / 2-5 / 2$ \\
\hline & & & & 54.77 & & $3 / 2-3 / 2$ \\
\hline \multirow[t]{4}{*}{55.12} & .10 & $3 \mathrm{dbl}$ & Si IX & 55.09 & $2 s^{2} 2 p^{2}{ }^{8} \mathrm{P}-3 s^{2} 2 p 3 d^{3} \mathrm{P}^{0}$ & $1-0$ \\
\hline & & & & 55.12 & & $1-1$ \\
\hline & & & & 55.23 & & $2-1$ \\
\hline & & & & 55.27 & & $2-2$ \\
\hline \multirow[t]{3}{*}{55.34} & .10 & $6 \mathrm{dbl}$ & Si IX & 55.30 & $2 s^{2} 2 p^{2}{ }^{3} \mathrm{P}-2 s^{2} 2 p 3 d^{3} \mathrm{D}^{0}$ & $0-1$ \\
\hline & & & & 55.36 & & $1-2$ \\
\hline & & & & 55.40 & & $2-3$ \\
\hline 56.03 & .05 & 1 & Si IX & 56.03 & $2 s^{2} 2 p^{2}{ }^{1} \mathrm{D}-2 s^{2} 2 p 3 d^{1} \mathrm{~F}^{0}$ & $2-3$ \\
\hline 56.64 & .05 & $0-1$ & Si X & 56.68 & $2 s 2 p^{2}{ }^{2} \mathrm{P}-2 s 2 p 3 s^{2} \mathrm{P}^{0}$ & $3 / 2-1 / 2,3 / 2$ \\
\hline 56.80 & .05 & $0-1$ & Si X & 56.80 & $2 s 2 p^{2}{ }^{2} \mathrm{P}-2 s 2 p 3 d^{2} \mathrm{D}^{0}$ & $3 / 2-5 / 2$ \\
\hline \multirow[t]{2}{*}{57.90} & .05 & 2 & Mg X & 57.88 & $2 s^{2} \mathrm{~S}-3 p^{2} \mathrm{P}^{0}$ & $1 / 2-3 / 2$ \\
\hline & & & & 57.92 & & $1 / 2-1 / 2$ \\
\hline \multirow[t]{2}{*}{ is . .0:3 } & .05 & $0-1 \mathrm{vd}$ & Si IX & 58.91 & $2 s 2 p^{3}{ }^{3} \mathrm{D}-2 s 2 p^{2} 3 d^{3} \mathrm{~F}^{0}$ & $3-4$ \\
\hline & & & & 59.00 & & $2-3$ \\
\hline \multirow[t]{3}{*}{ (; } & & & & 59.08 & & $1-2$ \\
\hline & & & Si VIII & 58.88 & $2 s^{2} 2 p^{3}{ }^{4} \mathrm{~S}^{0}-2 s 2 p^{3} 3 p^{4} \mathrm{P}$ & $3 / 2-1 / 2,3 / 2,5 / 2$ \\
\hline & & & (Fe XIV) & 58.96 & $3 s^{2} 3 p{ }^{2} \mathrm{P}^{0}-3 s^{2} 4 d^{2} \mathrm{D}$ & $1 / 2-3 / 2$ \\
\hline \multirow[t]{3}{*}{61.06} & .05 & $3 \mathrm{~d}$ & Si VIII & 60.99 & $2 s^{2} 2 p^{3}{ }^{4} \mathrm{~S}^{0}-2 s^{2} 2 p^{2} 3 d^{4} \mathrm{P}$ & $3 / 2-1 / 2$ \\
\hline & & & & 61.02 & & $3 / 2-3 / 2$ \\
\hline & & & & 61.07 & & $3 / 2-5 / 2$ \\
\hline \multirow[t]{4}{*}{61.51} & .05 & $1 \mathrm{bl}$ & Si IX & 61.50 & $2 s^{2} 2 p^{2}{ }^{3} \mathrm{P}-2 s^{2} 2 p 3 s^{3} \mathrm{P}^{0}$ & $1-2$ \\
\hline & & & & 61.55 & $2 s 2 p^{3}{ }^{3} \mathrm{D}^{0}-2 s 2 p^{\varepsilon} 3 s^{3} \mathrm{D}$ & $3-2,3$ \\
\hline & & & & 61.60 & $2 s^{2} 2 p^{2}{ }^{3} \mathrm{P}-2 s^{2} 2 p 3 s^{3} \mathrm{P}^{0}$ & $0-1$ \\
\hline & & & & 61.65 & & $2-2$ \\
\hline \multirow[t]{7}{*}{61.85} & .05 & $1 \mathrm{bl}$ & Si VIII & 61.80 & $2 s^{2} 2 p^{3}{ }^{2} \mathrm{D}^{0}-2 s^{2} 2 p^{2} 3 d^{2} \mathrm{D}$ & $5 / 2-5 / 2$ \\
\hline & & & & 61.85 & & $3 / 2-3 / 2$ \\
\hline & & & & 61.90 & $2 s^{2} 2 p^{3}{ }^{2} \mathrm{D}^{0}-2 s^{2} 2 p^{2} 3 d^{2} \mathrm{~F}$ & $3 / 2-5 / 2$ \\
\hline & & & & 61.91 & & $5 / 2-7 / 2$ \\
\hline & & & Si IX & 61.85 & $2 s^{2} 2 p^{2}{ }^{3} \mathrm{P}-2 s^{2} 2 p 3 s^{3} \mathrm{P}^{0}$ & $2-1$ \\
\hline & & & Mg IX & 61.92 & $2 s 2 p^{3} \mathrm{P}^{0}-2 p 3 p^{3} \mathrm{D}$ & $0,1,2-1,2,3$ \\
\hline & 05 & $1-2 \mathrm{bl}$ & Si VIII & $\begin{array}{l}61.96 \\
62.81\end{array}$ & $2 s^{2} 2 p^{3} \mathrm{P}^{0}-2 s^{2} 2 p^{2} 3 d^{2} \mathrm{P}$ & $\begin{array}{c}1-1 \\
3 / 2-3 / 2\end{array}$ \\
\hline \multirow{3}{*}{62.80} & .00 & $1-2 \mathrm{bl}$ & S1 VIII & $\begin{array}{l}02.81 \\
62.85\end{array}$ & $2 s-2 p-\mathrm{P}-2 s-2 p^{2}-3 a+\mathrm{F}$ & $\begin{array}{l}3 / 2-3 / 2 \\
1 / 2-1 / 2\end{array}$ \\
\hline & & & Mg IX & 62.75 & $2 s^{2}{ }^{1} \mathrm{~S}-2 d 3 p{ }^{1} \mathrm{P}^{0}$ & $0-1$ \\
\hline & & & (Fe XVI) & 62.88 & $3 p^{2} \mathrm{P}^{0}-4 s^{2} \mathrm{~S}$ & $1 / 2-1 / 2$ \\
\hline \multirow[t]{4}{*}{63.29} & .10 & $2 \mathrm{bl}$ & Si VIII & $\begin{array}{l}63.23 \\
63.27\end{array}$ & $2 s^{2} 2 p^{3} \mathbf{P}^{0}-2 s^{2} 2 p^{2} 3 d^{2} \mathrm{D}$ & $\begin{array}{c}3 / 2-3 / 2 \\
1-2\end{array}$ \\
\hline & & & S VIII & 63.70 & $2 s^{2} 2 p^{5}{ }^{2} \mathrm{P}^{0}-2 s^{2} 2 p^{4} 3 s^{2} \mathrm{P}$ & $2-2$ \\
\hline & & & $\operatorname{Mg} \mathbf{X}$ & 63.15 & $2 p^{2} \mathrm{P}^{0}-3 d^{2} \mathrm{D}$ & $1 / 2-3 / 2$ \\
\hline & & & & 63.29 & & $3 / 2-5 / 2$ \\
\hline \multirow[t]{2}{*}{63.73} & .05 & 1 & Fe XVI & 63.72 & $3 p^{2} \mathrm{P}^{0}-4 s^{2} \mathrm{~S}$ & $3 / 2-1 / 2$ \\
\hline & & & Si VIII & 63.73 & $2 s^{2} 2 p^{3}{ }^{2} \mathrm{D}^{0}-2 s^{2} 2 p^{2} 3 d^{2} \mathrm{~F}$ & $5 / 2-7 / 2$ \\
\hline 63.90 & .10 & $0-1$ & & 63.90 & & $3 / 2-5 / 2$ \\
\hline 65.67 & .05 & $0-1$ & Mg X & 65.67 & $2 p^{2} \mathrm{~F}^{0}-3 s^{2} \mathrm{~S}$ & $1 / 2-1 / 2$ \\
\hline 65.85 & .05 & 1 & & 65.85 & & $3 / 2-1 / 2$ \\
\hline 66.26 & .05 & 1 & Fe XVI & 66.26 & $3 d^{2} \mathrm{D}-4 f^{2} \mathrm{~F}^{0}$ & $3 / 2-5 / 2$ \\
\hline
\end{tabular}


TABLE I (cont)

\begin{tabular}{|c|c|c|c|c|c|c|}
\hline$\lambda_{\text {obs }}$ & $\Delta \lambda$ & $\mathbf{I}$ & & & IDENTIFTCATION & \\
\hline$\overline{c a}$ & $\overline{05}$ & - & & & $3 d^{2} \overline{\Delta+2 \mathrm{FO}}$ & \\
\hline 66.37 & .05 & $0-1$ & Fe XVI & 66.37 & $3 d^{2} \mathrm{D}-4 f^{2} \mathrm{~F}^{0}$ & $5 / 2-7 / 2$ \\
\hline \multirow[t]{2}{*}{67.15} & .10 & $1 \mathrm{~d}$ & Mg IX & $\begin{array}{l}67.09 \\
67.14\end{array}$ & $2 s 2 p^{3} \mathrm{P}^{0}-2 s 3 d^{3} \mathrm{D}$ & $\begin{array}{l}0-1 \\
1-2\end{array}$ \\
\hline & & & & 67.24 & & $2-3$ \\
\hline \multirow[t]{3}{*}{69.99} & .10 & $1 \mathrm{bl}$ & Mg IX & 69.95 & $2 p^{2}{ }^{1} \mathrm{D}-2 p 3 d^{1} \mathrm{~F}^{0}$ & $2-3$ \\
\hline & & & $(\mathrm{Fe} \mathrm{XV})$ & $\begin{array}{l}69.95 \\
69.99\end{array}$ & $3 s 3 d^{3} \mathrm{D}-3 s 4 f^{3} \mathrm{~F}^{0}$ & $\begin{array}{l}1-2 \\
2-3\end{array}$ \\
\hline & & & & 70.05 & & $3-4$ \\
\hline \multirow[t]{2}{*}{72.26} & .05 & $1 \mathrm{~d}$ & Mg IX & 72.23 & $2 p^{2}{ }^{1} \mathrm{D}-2 p 3 d^{1} \mathrm{D}^{0}$ & $2-2$ \\
\hline & & & & 72.31 & $2 s 2 p^{1} \mathrm{P}^{0}-2 s 3 d^{1} \mathrm{D}$ & $1-2$ \\
\hline \multirow[t]{2}{*}{150.10} & .03 & 0 & O VI & 150.09 & $2 s^{2} \mathrm{~S}-3 p^{2} \mathrm{P}^{0}$ & $1 / 2-3 / 2$ \\
\hline & & & & 150.12 & & $1 / 2-1 / 2$ \\
\hline 172.17 & .03 & 3 & $\mathrm{OV}$ & 172.17 & $2 s^{2}{ }^{1} \mathrm{~S}-2 s 3 p^{1} \mathrm{P}^{0}$ & $0-1$ \\
\hline 172.94 & .03 & 4 & O VI & 172.94 & $2 p^{2} \mathrm{P}^{0}-3 d^{2} \mathrm{D}$ & $3 / 2-5 / 2$ \\
\hline 173.09 & .03 & 7 & & 173.08 & & $1 / 2-3 / 2$ \\
\hline 183.94 & .03 & 3 & O VI & 183.94 & $2 p^{2} \mathrm{P}^{0}-3 s^{2} \mathrm{~S}$ & $1 / 2-1 / 2$ \\
\hline 184.12 & .03 & 5 & & 184.12 & & $3 / 2-1 / 2$ \\
\hline 185.74 & .05 & 0 & $\mathrm{OV}$ & 185.75 & $2 s 2 p^{1} \mathrm{P}^{0}-2 p 3 p^{1} \mathrm{D}$ & $1-2$ \\
\hline \multirow[t]{3}{*}{192.84} & .10 & $14 \mathrm{bl}$ & $\mathrm{OV}$ & 192.75 & $2 s 2 p^{3} \mathrm{P}^{0}-2 s 3 \bar{d}^{3} \mathrm{D}$ & $0-1$ \\
\hline & & & & 192.80 & & $1-2$ \\
\hline & & & & 192.91 & & $2-3$ \\
\hline 194.58 & .05 & 2 & $\mathrm{OV}$ & 194.59 & $2 s 2 p^{1} \mathrm{P}^{0}-2 p 3 p^{1} \mathrm{P}$ & $1-1$ \\
\hline 207.79 & .10 & $5 \mathrm{bl}$ & $\mathrm{OV}$ & 207.79 & $2 p^{2}{ }^{1} \mathrm{D}-2 p 3 d^{1} \mathrm{~F}^{0}$ & $1-2$ \\
\hline \multirow{3}{*}{215.10} & .10 & $3 \mathrm{bl}$ & $\mathrm{OV}$ & 215.03 & $2 s 2 p^{3} \mathrm{P}^{0}-2 s 3 s^{3} \mathrm{~S}$ & $0-1$ \\
\hline & & & & 215.10 & & $1-1$ \\
\hline & & & & 215.24 & & $2-1$ \\
\hline 216.04 & .10 & $1-2$ & $0 \mathrm{~V}$ & 216.02 & $2 p^{2}{ }^{1} \mathrm{D}-2 p 3 d^{1} \mathrm{D}^{0}$ & $2-2$ \\
\hline 220.34 & .10 & $10 \mathrm{wbl}$ & $\mathrm{OV}$ & 220.35 & $2 s 2 p^{1} \mathrm{P}^{0}-2 s 3 d^{1} \mathrm{D}$ & $1-2$ \\
\hline 223.70 & .10 & $5 \mathrm{dbl}$ & Si IX & 223.72 & $2 s^{2} 2 p^{2}{ }^{3} \mathrm{P}-2 s 2 p^{3}{ }^{3} \mathrm{~S}^{0}$ & $0-1$ \\
\hline 224.69 & .10 & $5 \mathrm{bl}$ & S IX & {$[224.7]$} & $2 s^{2} 2 p^{4}{ }^{3} \mathrm{P}-2 s 2 p^{5}{ }^{3} \mathrm{P}^{0}$ & $2-2$ \\
\hline (2).08 & .10 & $12 \mathrm{bl}$ & Si IX & 225.03 & $2 s^{2} 2 p^{2}{ }^{3} \mathrm{P}-2 s 2 p^{3}{ }^{3} \mathrm{~S}^{0}$ & $1-1$ \\
\hline 227.06 & .05 & 12 & Si IX & 227.01 & & $2-1$ \\
\hline 23145 & .10 & $2 \mathrm{bl}$ & He II & 231.45 & $1 s^{2} \mathrm{~S}-8 p^{2} \mathrm{P}^{0}$ & $1 / 2-1 / 2,3 / 2$ \\
\hline $232 .-69$ & .05 & 2 & He II & 232.58 & $1 s^{2} \mathrm{~S}-7 p^{2} \mathrm{P}^{0}$ & $1 / 2-1 / 2,3 / 2$ \\
\hline 234.37 & .10 & $6 \mathrm{bl}$ & He II & 234.35 & $1 s^{2} \mathrm{~S}-6 p^{2} \mathrm{P}^{0}$ & $1 / 2-1 / 2,3 / 2$ \\
\hline 237.32 & .05 & 7 & He II & 237.33 & $1 s{ }^{2} \mathrm{~S}-5 p^{2} \mathrm{P}^{0}$ & $1 / 2-1 / 2,3 / 2$ \\
\hline 243.06 & .05 & 10 & He II & 243.03 & $1 s^{2} S-4 p^{2} \mathrm{P}^{0}$ & $1 / 2-1 / 2,3 / 2$ \\
\hline 253.80 & .05 & 5 & Si $X$ & 253.81 & $2 s^{2} 2 p^{2} \mathbf{P}^{0}-2 s 2 p^{2}{ }^{2} \mathrm{D}$ & $1 / 2-3 / 2$ \\
\hline 256.32 & .05 & 30 & $\mathrm{He}$ II & 256.32 & $1 s^{2} S^{2}-3 p^{2} \mathrm{P}^{0}$ & $1 / 2-1 / 2,3 / 2$ \\
\hline 257.29 & .05 & 20 & $\mathrm{Sx}$ & {$[257.30]$} & $2 s^{2} 2 p^{3}{ }^{4} \mathrm{~S}^{0}-2 s 2 p^{4}{ }^{4} \mathrm{P}$ & $3 / 2-1 / 2$ \\
\hline 258.38 & .05 & 12 & Si X & 258.39 & $2 s^{2} 2 p^{2} \mathrm{P}^{0}-2 s 2 p^{2}{ }^{2} \mathrm{P}$ & $3 / 2-3 / 2$ \\
\hline 259.53 & .05 & 4 & $\mathrm{SX}$ & {$[259.56]$} & $2 s^{2} 2 p^{3}{ }^{4} \mathrm{~S}^{0}-2 s 2 p^{4}{ }^{4} \mathrm{P}$ & $3 / 2-3 / 2$ \\
\hline 264.29 & .05 & 5 & $\mathrm{~S} X$ & {$[264.28]$} & & $3 / 2-5 / 2$ \\
\hline 271.99 & .05 & 6 & Si $X$ & 272.00 & $2 s^{2} 2 p^{2} \mathrm{P}^{0}-2 \varepsilon^{2} p^{2}{ }^{2} \mathrm{~S}$ & $1 / 2-1 / 2$ \\
\hline 275.33 & .05 & 3 & Si VII & 275.35 & $2 s^{2} 2 p^{4}{ }^{3} \mathrm{P}-2 s 2 p^{5}{ }^{3} \mathrm{P}^{0}$ & $2-2$ \\
\hline \multirow[t]{3}{*}{277.10} & .10 & $7 \mathrm{~d} \mathrm{bl}$ & Si VIII & 276.84 & $2 s^{2} 2 p^{3}{ }^{2} \mathrm{D}^{0}-2 s 2 p^{4}{ }^{2} \mathrm{D}$ & $3 / 2-3 / 2$ \\
\hline & & & & 277.05 & & $5 / 2-5 / 2$ \\
\hline & & & $(\mathrm{Si} \mathrm{X})$ & 277.27 & $2 s^{2} 2 p^{2} \mathrm{P}^{0}-2 s 2 p^{2}{ }^{2} \mathrm{~S}$ & $3 / 2-1 / 2$ \\
\hline \multirow{2}{*}{278.44} & .05 & 3 & Mg VII & 278.40 & $2 s^{2} 2 p^{2}{ }^{3} \mathrm{P}-2 s 2 p^{3}{ }^{3} \mathrm{~S}^{0}$ & $2-1$ \\
\hline & & & $\mathrm{Si}$ VII & 278.44 & $2 s^{2} 2 p^{4}{ }^{3} \mathrm{P}-2 s 2 p^{5}{ }^{3} \mathrm{P}^{0}$ & $1-2$ \\
\hline 284.11 & .05 & 30 & $\mathrm{Fe} X V$ & 284. & $3 s^{2}{ }^{1} \mathrm{~S}-3 s 3 p^{1} \mathbf{P}^{0}$ & $0-1$ \\
\hline 290.68 & .10 & $3 \mathrm{~d}$ & Si IX & 290.63 & $2 s^{2} 2 p^{2}{ }^{3} \mathrm{P}-2 s 2 p^{3}{ }^{3} \mathrm{P}^{0}$ & $0-1$ \\
\hline 292.79 & .05 & 5 & Si IX & 292.83 & $2 s^{2} 2 p^{2}{ }^{3} \mathrm{P}-2 s 2 p^{3}{ }^{3} \mathrm{P}^{0}$ & $1-0,1,2$ \\
\hline
\end{tabular}


TABLE I (cont)

\begin{tabular}{|c|c|c|c|c|c|c|}
\hline \multirow{2}{*}{$\lambda_{\text {obs }}$} & \multirow{3}{*}{$\frac{\Delta \lambda}{.05}$} & \multirow{2}{*}{ I } & \multicolumn{4}{|c|}{ IDEXTIFTCATION } \\
\hline & & & & & $90^{2} 9 m^{2} 3 \mathrm{P}-909 m^{3} 3 \mathrm{po}$ & \\
\hline 296.17 & & 6 & Si IX & 296.19 & $2 s^{2} 2 p^{23} \mathrm{P}-2 s 2 p^{3}{ }^{3} \mathrm{P}^{0}$ & $2-2$ \\
\hline 303.37 & .10 & 5 & Si XI & {$[303.41]$} & & $0-1$ \\
\hline 303.79 & .05 & 100 & $\mathrm{He}$ II & 303.79 & $1 s^{2} \mathrm{~S}-2 p^{2} \mathrm{P}^{0}$ & $1 / 2-1 / 2,3 / 2$ \\
\hline 308.33 & .10 & 2 & Si VIII & 308.26 & $2 s^{2} 2 p^{3}{ }^{2} \mathrm{P}^{0}-2 s 2 p^{4}{ }^{2} \mathrm{D}$ & $3 / 2-3 / 2,5 / 2$ \\
\hline 311.96 & .20 & $4 \mathrm{wbl}$ & (Mg VIII) & 311.78 & $2 s^{2} 2 p^{2} \mathrm{P}^{0}-2 s 2 p^{2}{ }^{2} \mathrm{P}$ & $1 / 2-3 / 2$ \\
\hline 313.75 & .10 & $2 \mathrm{bl}$ & Mg VIII & 313.73 & & $1 / 2-1 / 2$ \\
\hline 314.29 & .10 & $2 \mathrm{bl}$ & Si VIII & 314.31 & $2 s^{2} 2 p^{3}{ }^{4} S^{0}-2 s 2 p^{4}{ }^{4} \mathrm{P}$ & $3 / 2-1 / 2$ \\
\hline 314.99 & .05 & 5 & Mg VIII & 315.02 & $2 s^{2} 2 p^{2} \mathrm{P}^{0}-2 s 2 p^{2}{ }^{2} \mathrm{P}$ & $3 / 2-3 / 2$ \\
\hline 316.19 & .05 & 4 & Si VIII & 316.20 & $2 s^{2} 2 p^{3}{ }^{4} S^{0}-2 s 2 p^{4}{ }^{4} \mathrm{P}$ & $3 / 2-3 / 2$ \\
\hline 317.01 & .05 & 2 & Mg VIII & 317.01 & $2 s^{2} 2 p^{2} \mathrm{P}^{0}-2 s 2 p^{2}{ }^{2} \mathrm{P}$ & $3 / 2-1 / 2$ \\
\hline 319.79 & .05 & 4 & Si VIII & 319.83 & $2 s^{2} 2 p^{3}{ }^{4} S^{0}-2 s 2 p^{4}{ }^{4} \mathrm{P}$ & $3 / 2-5 / 2$ \\
\hline 332.81 & .05 & 3 & Al $\mathbf{X}$ & {$[332.84]$} & $2 s^{2}{ }^{1} \mathrm{~S}-2 s 2 p^{1} \mathrm{P}^{0}$ & $0-1$ \\
\hline 335.31 & .10 & 10 & Fe XVI & [335.4 ] & $3 s^{2} \mathrm{~S}-3 p^{2} \mathrm{P}^{0}$ & $1 / 2-3 / 2$ \\
\hline 339.00 & .10 & 1 & Mg VIII & 339.01 & $2 s^{2} 2 p^{2} \mathrm{P}^{0}-2 s 2 p^{2}{ }^{2} \mathrm{~S}$ & $3 / 2-1 / 2$ \\
\hline 345.07 & .10 & 3 & Si IX & 345.10 & $2 s^{2} 2 p^{2}{ }^{3} \mathrm{P}-2 s 2 p^{3}{ }^{3} \mathrm{D}^{0}$ & $1-2$ \\
\hline 347.39 & .05 & 4 & Si X & 347.43 & $2 s^{2} 2 p^{2} \mathrm{P}^{0}-2 s 2 p^{2}{ }^{2} \mathrm{D}$ & $1 / 2-3 / 2$ \\
\hline 349.93 & .10 & 4 & Si IX & 349.96 & $2 s^{2} 2 p^{2}{ }^{3} \mathrm{P}-2 s 2 p^{3}{ }^{3} \mathrm{D}^{0}$ & $2-3$ \\
\hline \multirow[t]{2}{*}{356.04} & .10 & $4 \mathrm{bl}$ & (Mg VIII) & 356.00 & $2 s 2 p^{2}{ }^{4} \mathrm{P}-2 p^{3}{ }^{4} \mathrm{~S}^{0}$ & $5 / 2-3 / 2$ \\
\hline & & & Si X & 356.07 & $2 s^{2} 2 p^{2} \mathrm{P}^{0}-2 s 2 p^{2}{ }^{2} \mathrm{D}$ & $3 / 2-5 / 2$ \\
\hline 360.81 & .20 & $25 \mathrm{bl}$ & (Fe XVI) & {$[360.7]$} & $3 s{ }^{2} \mathrm{~S}-3 p{ }^{2} \mathrm{P}^{0}$ & $1 / 2-1 / 2$ \\
\hline 365.31 & .10 & $2 \mathrm{~d}$ & (Mg VII) & 365.24 & $2 s^{2} 2 p^{2}{ }^{3} \mathrm{P}-2 s 2 p^{3}{ }^{3} \mathrm{P}^{0}$ & $1-1,2$ \\
\hline 368.08 & .05 & $15 \mathrm{bl}$ & Mg IX & 368.07 & $2 s^{2}{ }^{1} \mathrm{~S}-2 s 2 p^{1} \mathrm{P}^{0}$ & $0-1$ \\
\hline 430.47 & .10 & $1 \mathrm{bl}$ & (Mg VIII) & 430.47 & $2 s^{2} 2 p^{2} \mathrm{P}^{0}-2 s 2 p^{2}{ }^{2} \mathrm{D}$ & $1 / 2-3 / 2$ \\
\hline \multirow[t]{2}{*}{436.70} & .10 & $2 \mathrm{bl}$ & (Mg VIII) & 436.68 & & $3 / 2-3 / 2$ \\
\hline & .10 & & & 436.72 & & $3 / 2-5 / 2$ \\
\hline 465.30 & .10 & $2 \mathrm{bl}$ & $\mathrm{Ne}$ VII & {$[465.2]$} & $2 s^{2}{ }^{1} \mathrm{~S}-2 s 2 p^{1} \mathrm{P}^{0}$ & $0-1$ \\
\hline 499.47 & .10 & $2 \mathrm{dbl}$ & (Si XII) & {$[499.2]$} & $2 s^{2} \mathrm{~S}-2 p^{2} \mathrm{P}^{0}$ & $1 / 2-3 / 2$ \\
\hline
\end{tabular}

nothing was known until 1963 are the strong lines from $171 \AA$ to $220 \AA$. In intensity these lines add to more than three times the intensity of He II, 303.78 $\AA$ (Hinteregakr, HaLL, and SchMIтDKe, 1964). Within this wavelength range only a few faint lines of $\mathrm{OV}$ and $\mathrm{O}$ VI have been identified, but these, together with the Lyman series of $\mathrm{He}$ II, served to establish wavelengths.

The first light was thrown on the identity of the lines from $171 \AA$ to $212 \AA$ by FAwCETT, Gabriel, Griffin, Jones, and Wirson (1963). Using the magnetically compressed Zeta discharge at Harwell, England, they obtained a spectrum, a portion of which is reproduced in Figure 7. This is enlarged so as approximately to match in dispersion the spectrum of the Sun photographed by NRL on September 20, 1963. FAWCETT et al. pointed out that most of the lines from Zeta, and especially the strongest lines, coincided with lines in the solar spectrum. They showed that the lines in Zeta were produced by material from the walls which are of stainless steel. It appeared reasonable therefore to attribute them to iron in high stages of ionization, such as those which exist in the Sun's corona, or in Zeta, whose electron temperature is of the order of $10^{6} \mathrm{~K}$, as derived from measurements of HEROUX (1964).

Further work has been carried out by studying the spectrum of the high temperature electrodeless discharge known as $\theta$-pinch, first when free from iron and then after introduction of iron. In this way Elton, Kolb, Austin, Tousey, and WIDING (1964) found that eighteen lines in the solar spectrum coincided with lines present in $\theta$-pinch when iron was added. Most of these lines were the same as those already found in Zeta. Similar results have been obtained by House and SAWYer (1964), and by FAWCETT and GABRIEL (1965), as reported in a later paper by WiLson. It is well established, therefore, that many of these intense lines are to be ascribed to iron.

The question remains as to the ionization stages of iron responsible for these solar lines. The difficulty in identification comes from the lack of laboratory observation of the spectrum of 
iron in intermediate and high stages of ionization in the wavelength range $150 \AA$ to $240 \AA$. The available data are insufficient to permit making extrapolations down the isoelectronic sequences with the required accuracy. In the solar spectrum there is also the problem of overlapping multiplets, blending, and so forth, even with the resolution attained on September 20, 1963. As pointed out by ELToN, et al. (1964), however, it is unlikely that these lines can be ascribed to the $3 d^{k}-3 d^{k-1} 4 p$ transitions of Fe IV-VIII, or to the $3 p^{6}-3 p^{5}(4 d, 4 s)$ transitions in $\mathrm{Fe} \mathrm{IX}$.
On the other hand, the transitions in $\mathbf{F e}$ VIII-XIII of the type $3 s^{2} 3 p^{k}-3 s^{2} 3 p^{k-1} 3 d$ should fall in the wavelength range $170 \AA$ to $220 \AA$. These ions are high chromospheric or coronal, since the ionization potential of Fe IX is $235 \mathrm{eV}$, and of Fe XIII is $355 \mathrm{eV}$. Further clues will be discussed later in connection with spectroheliograms.

The identification of a line at $182.2 \AA$ as the $\mathrm{H} \alpha$ line of C VI was suggested by ToUSEY (1962). Doubt is now thrown on this by the spectra obtained from Zeta and $\theta$-pinch. In Figure 8
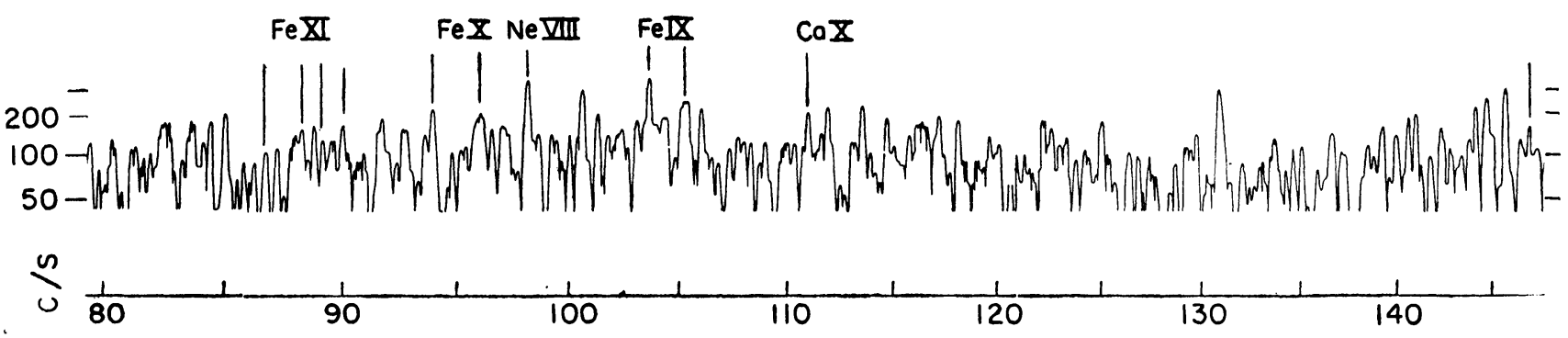

Fia. 5. - The solar spectrum as rocorded on May 2, 1963 by ths Air Fores Cambridge R3.suarcil Laboratories.

there is shown an enlargement of a section of the September 20, 1963 spectrum. It can be seen that the line at $182.2 \AA$ is actually a blend of two lines, which are well separated at the increased resolution. As pointed out by ELToN et al. (1964), the stronger component, whose wavelength is $182.17 \AA$, is in good agreement with a strong line occurring in both Zeta and in the iron-loaded $\theta$-pinch. Therefore, an iron line must have made the principal contribution to the line identified as $C$ VI in the early, low-resolution solar spectra. The faint line at 182.30 $\AA$, however, may perhaps be identified as C VI, which has several components, the strongest at $182.23 \AA$ and the next strongest at $182.09 \AA$; however, the components at $182.25 \AA$ and $182.29 \AA$ are relatively weak, hence the identification is regarded as doubtful. On the other hand, the Lyman-alpha line of C VI, 33.7 $\AA$ is intense in the solar spectrum, and at shorter wavelengths Ly $\alpha$ of both N VII and O VIII have been observed by BLAkE et al. (1964). Ly $\beta$ of N VII and $O$ VIII were also recorded, but Ly $\beta$ of $\mathrm{C} V I$ lies at $28.5 \AA$, a region not yet covered. Since the Ly $\beta$ lines of N VII and O VIII are present and Ly $\beta$ of $C$ VI cannot be said to be absent, it seems reasonable to expect the $H_{\alpha}$ lines of C VI, $\mathrm{N}$ VII, and $\mathrm{O}$ VIII. However, $\mathrm{H} \alpha$ of N VII, $133.9 \AA$ and of $O$ VIII, $102.5 \AA$, do not show in Figure 5. Further work is required.
Lines of high stages of ionization of iron are present in the corona, of course, as has been known since the original identification by EDLEN (1942) of the $5303 \AA$ line as from Fe XIV. The principal resonance lines of these ions all lie in the extreme ultraviolet and soft $X$-ray range, and for Fe XIV, XV, and XVI they fall in the region covered by Figure 3.

The resonance line of $\mathrm{Fe} \mathrm{XV}, 3 s^{2}{ }^{1} \mathrm{~S}-3 s 3 p{ }^{1 \mathrm{P}^{0}}$, 284.1 $\AA$, was identified by EDLEN (1962) in the spectrum of Austin, PURcell, and Tousey (1962). The resonance lines of $\mathrm{Fe} \mathrm{XVI}, 3 s^{2} \mathrm{~S}-3 p^{2} \mathrm{P}$, corresponding to the $\mathrm{D}$-lines of sodium, should have wavelengths $335.0,360.3 \AA$, according to an extrapolation by EDLÉ (1962). The strong lines present at $335 \AA$ and $362 \AA$ in the photoelectric spectrum obtained by HINTEREGGER (1961) on August 23, 1960 were tentatively identified as these lines of Fe XVI, (Tousey, 1961). The observed intensity ratio, 2:1 approximately, supported this identification. Although the same lines were also present in the photographic spectrum of Adstin, Tousey, and Purcell (1962), the line at $361 \AA$ was far too strong, because the second order of the line at $180.4 \AA$, with which it was blended, was much stronger than in the photoelectric spectrum; hence it could not be used to confirm the presence of the Fe XVI doublet. In the later photographic spectra of higher resolution, however, the presence of Fe XVI has 
been confirmed; the observed wavelengths are $335.31 \AA$ and $360.82 \AA$, the latter determined simply by assuming that this line is perfectly blended with the second order of $180.41 \AA$. Further confirmation is provided by the spectroheliograms shown in Figures 10 and 11, where both iron lines are clearly present in the emission from active regions, but the second order blend is not, as will be discussed later. Lines of Fe XVII, the next higher stage of ionization, have been found by Blake, UNZICKer, ChUBb, and FrIedmaN (1964), as will be described in Dr. ChUBB's paper ; these, also, are relatively intense. They are from transitions in which the principal quantum number changes from 3 to 2 , and lie at 16.77, $16.00,15.26,15.01$, and perhaps $13.8 \AA$.

The situation in the case of Fe XIV, however, is quite uncertain at the present time. Portions of the May 10, 1963 spectrum where the strongest resonance lines should appear are shown in Figure 9. The observed lines which come closest to the predicted wavelengths and intervals are listed in Table II. The difficulty is that the Fe XIV lines have never been observed in the laboratory. Their wavelengths must be obtained by extrapolation, five steps beyond Sc IX, the highest member of the sequence studied. The extrapolation is believed to be correct within
$2 \AA$ for the P-P multiplet, and within $2 \AA$ to $4 \AA$ for the P-D and P-S multiplets. However, the ground term splitting ${ }^{2} \mathrm{P}_{\mathbf{3} / \mathbf{2} \cdot \mathbf{1} / \mathbf{2}}$, is known precisely from the wavelength of the $5303 \AA$ line. Therefore, the exact separation between pairs of lines can be calculated, even though the wavelengths cannot. Shown in Table II are the observed and computed wavelength separations for the four pairs of lines for which this check can be made. Although the errors, shown in Figure 9, are not large, $0.1 \AA$ is somewhat too great, and $0.21 \AA$ is certainly beyond the experimental error. Equally serious is the nearly complete disagreement between the observed intensities and the values of $\omega f$ computed by GARSTANG (1962). It seems probable that other lines are present, producing blends and masking the lines of Fe XIV. This is obviously the case for the P-P multiplet, since the line at $264.29 \AA$ that should be the strongest is actually the weakest of all, in spite of the fact that it is blended with the strongest component of a multiplet of, S X, which contains three lines, and $\lambda 257.32 \AA$ is certainly a blend. The P-D multiplet, for which the wavelength separation is satisfactory, shows intensities that run exactly contrary to prediction. The P-S multiplet is the only one for which the agreement is fairly good in both separation and

\section{TABLE II}

\section{Fe XIV}

\begin{tabular}{|c|c|c|c|c|c|c|c|c|}
\hline Transition & $\underline{\Delta}$ & OBs. $\lambda$ & $\begin{array}{c}\text { EXTRAP. } \lambda \\
-\end{array}$ & Oвs. $\Delta \bar{\lambda}$ & CaLC. $\Delta \lambda$ & OBs. I & CaLc. I & Notes \\
\hline \multirow[t]{2}{*}{$3 s^{2} 3 p^{2} \mathrm{P}^{0}-3 s 3 p^{2}{ }^{2} \mathrm{P}$} & $\begin{array}{l}1 / 2-1 / 2 \\
3 / 2-1 / 2\end{array}$ & $\begin{array}{l}257.32 \\
270.57\end{array}$ & $\left.\begin{array}{c}257.38 \\
271.51\end{array}\right\}$ & 13.25 & 13.13 & $\begin{array}{l}7 \\
3\end{array}$ & $\begin{array}{l}0.32 \\
0.51\end{array}$ & masked \\
\hline & $\begin{array}{l}1 / 2-3 / 2 \\
3 / 2-3 / 2\end{array}$ & $\begin{array}{l}251.96 \\
364.29\end{array}$ & $\left.\begin{array}{l}251.75 \\
264.29^{*}\end{array}\right\}$ & 12.33 & 12.54 & $\begin{array}{l}4 \\
3\end{array}$ & $\begin{array}{l}0.36 \\
1.60\end{array}$ & $\begin{array}{l}\text { blended } \\
\text { bl. SX }\end{array}$ \\
\hline $3 s^{2} 3 p^{2} \mathrm{P}^{0}-3 s 3 p^{2}{ }^{2} S$ & $\begin{array}{l}1 / 2-1 / 2 \\
3 / 2-1 / 2\end{array}$ & $\begin{array}{l}274.23 \\
289.31\end{array}$ & $\left.\begin{array}{l}274.23^{*} \\
289.17\end{array}\right\}$ & 15.08 & 14.94 & $\begin{array}{l}4 \\
0\end{array}$ & $\begin{array}{l}0.43 \\
0.02\end{array}$ & \\
\hline \multirow[t]{2}{*}{$3 s^{2} 3 p^{2} \mathrm{P}^{0}-3 s^{2} 3 d^{2} \mathrm{D}$} & $\begin{array}{l}1 / 2-3 / 2 \\
3 / 2-3 / 2\end{array}$ & $\begin{array}{l}211.32 \\
220.16\end{array}$ & $\begin{array}{l}211.39 \\
220.16\end{array}$ & 8.84 & 8.77 & $\begin{array}{l}7 \\
4\end{array}$ & $\begin{array}{l}1.10 \\
0.29\end{array}$ & masked \\
\hline & $3 / 2-5 / 2$ & 219.04 & $219.10^{*}$ & & & 3 & 2.00 & \\
\hline $3 s^{2} 3 p^{2} \mathrm{P}^{0}-3 s^{3} p^{2}{ }^{2} \mathrm{D}$ & $\begin{array}{l}1 / 2-3 / 2 \\
3 / 2-3 / 2 \\
3 / 2-5 / 2\end{array}$ & $\begin{array}{l}\text { blends } \\
\text { blends } \\
\text { blends }\end{array}$ & $\begin{array}{l}338 \\
361 \\
358\end{array}$ & & & & $\begin{array}{l}0.15 \\
0.005 \\
0.20\end{array}$ & \\
\hline
\end{tabular}

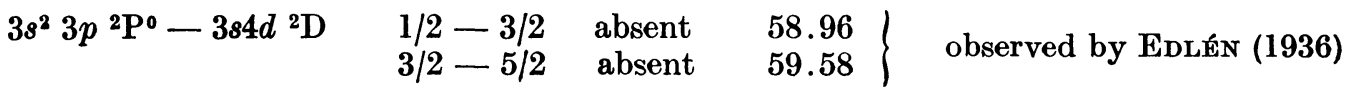

Values of I are those calculated by Garstang (1962).

Extrapolated $\lambda$ values were calculated by Widing (unpublished); for the first three multiplets the line * was assumed, and the other lines were calculated using observed and extrapolated term splittings. 
intensity. The long wavelength member is extremely faint but can be seen in the original, or in a print if looked at edge-on. Lacking proof of the presence of the other Fe XIV multiplets, we regard even the P-S multiplet as extremely doubtful. Identification of $\mathrm{Fe} \mathrm{XIV} 3 s^{2} 3 p{ }^{2} \mathrm{P}^{0}-3 s 3 p^{2}{ }^{2} \mathrm{D}$, producing three lines near $350 \AA$, seems to be nearly hopeless at present, since these lines fall in a region which is filled with many lines of both first and second order, and since the extrapolated wavelengths are so inexact. It can be said, however, that no first order lines are present which stand out like Fe XVI, $335 \AA$.

In the X-ray range, two lines of Fe XIV, $3 s^{2} 3 p^{2} \mathrm{P}^{0}-3 s^{2} 4 d^{2} \mathrm{D}$ might be expected, since Fe XVI, $3 s{ }^{2} \mathrm{~S}_{1 / 2}-4 p{ }^{2} \mathrm{P}_{3 / 2}^{0}, 50.35 \AA$ and several other lines of Fe XVI are present ; they could not be found.

From studies of the variation of the intensity of various lines with solar activity, as observed from OSO-I, NeUPERT and SMITH (1964) suggested the same lines as are shown in Table II for the Fe XIV, P-S and P-P multiplets ; they found, however, that the intensities of the lines of the P-D multiplet vary in a different way and suggested, instead, $211 \AA$ and $204 \AA$ for $3 / 2-5 / 2$ and $1 / 2-3 / 2$, respectively, which vary in the same way. It is unlikely, however, that the extrapolation can be in error by as much as $8 \AA$. Furthermore, the wavelengths of these lines, as determined from the May 10, 1963 spectrum, were 211.30 and $203.80 \AA$, but the $\Delta \lambda$ value, calulated from the term splitting, is $7.2 \AA, 0.3 \AA$ less than the observed value. Since both lines are present in Zeta and $\theta$-pinch, they are most probably iron, but in a stage of ionization lower than $\mathrm{Fe}$ XIV, which has not yet been observed in these plasmas.

Stages of ionization lower than Fe XIV have not been proved to be present as yet, although forbidden coronal lines of Fe X-XIII have been identified in the near ultraviolet, visible and infrared. As was discussed, they probably account for much of the strong spectrum from $171 \AA$ to $220 \AA$. The transitions involving a change in principal quantum number for Fe IX-XIII lie in the range $103 \AA$ to $75 \AA$. ZIRIN (1964) has suggested that they are present in the photoelectric spectra. The most probable appear to be the lines of $\mathrm{Fe}$ IX-XI, indicated in Figure 5. However, these lines are so weak that they are regarded as uncertain until confirmed by more intense spectra.

The conclusion regarding iron is that the principal resonance lines of Fe XVII, XVI, and XV are emitted with relatively great intensity, whereas those of Fe XIV are weak. Some ions in the range Fe IX-XIII produce intense lines, but further analysis is required to determine which produce the strong lines.

In the X-ray range, Figure 6, in sharp contrast to the region $\lambda<148 \AA$, almost all the lines have been identified. Generally, all the lines that would be expected, are found to be present, and with reasonably correct relative intensities. In Table I all the lines observed at $\lambda<80 \AA$, are listed, and identifications are given. In addition to Ly $\alpha$ of C VI, 33.7 $\AA$, the two resonance lines of helium-like $\mathrm{C} \mathrm{V}$ are present ; the stronger, $40.26 \AA$, is the transition ${ }^{1} \mathrm{P}-{ }^{1} \mathrm{~S}$; a line at $40.70 \AA$, which is clearly visible on the original, is identified as ${ }^{3} \mathrm{P}$ - ' $\mathrm{S}$. As was pointed out by EDLÉN (1951), the intersystem line becomes stronger relative to the singlet system, the farther the ion lies down the isoelectronic sequence; this explains why the triplet to singlet line of $\mathrm{C} \mathrm{V}$ is present in the solar spectrum, whereas the corresponding line of $\mathrm{He} \mathrm{I}, 591.420 \AA$ has not been detected.

An intriguing possibility is that the faint line at $43.25 \AA$ is the second order of Ly $\alpha$ of 0 VII, $21.60 \AA$, which was the strongest of the lines recorded photoelectrically by BLAKE, UNzICKER, Chubb, and Friedman (1964). The intersystem line, $21.80 \AA$, cannot be seen, but its second order, lying on $0.16 \AA$ from Si XI, 43.76 $\AA$, and having less than one-half the intensity of the $21.6 \AA$ line, would not be distinguishable in the photographic spectrum. An image at $21.6 \AA$ in the first order could not be found, but instrumental broadening effects are sufficient to explain its absence.

Among the other identifications are various lines of Si VIII, X, XI, and XII and of Mg IX and $X$, as shown in Table $I$. The intensity ratio between lines in this wavelength range and those from the same ions at much longer wavelengths, have been determined and will be interpreted in a subsequent paper by WIDING.

A summary of the elements and ionic species which have been found in the Sun through iron is presented in Table III, where solid bars indicate species for which lines in the extreme ultraviolet have been found. Isoelectronic sequences appear on this plot as diagonal lines at $45^{\circ}$. Contours are introduced to indicate, roughly, the ionization potentials to produce the various ionic species. Their meaning is best explained by an example; $100 \mathrm{eV}$ will produce all oxygen ions 


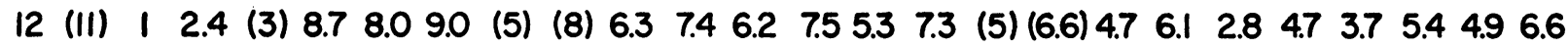
$\mathrm{H} \mathrm{He} \mathrm{Li} \mathrm{Be} B \quad \mathrm{C} \quad \mathrm{N} O \mathrm{~F} \mathrm{Ne} \mathrm{NaMg} \mathrm{Al} \mathrm{Si} \mathrm{P} \mathrm{S} \mathrm{Cl} \mathrm{Ar} \mathrm{K} \mathrm{Ca} \mathrm{Se} \mathrm{Ti} \mathrm{V}$ Cr Mn Fe

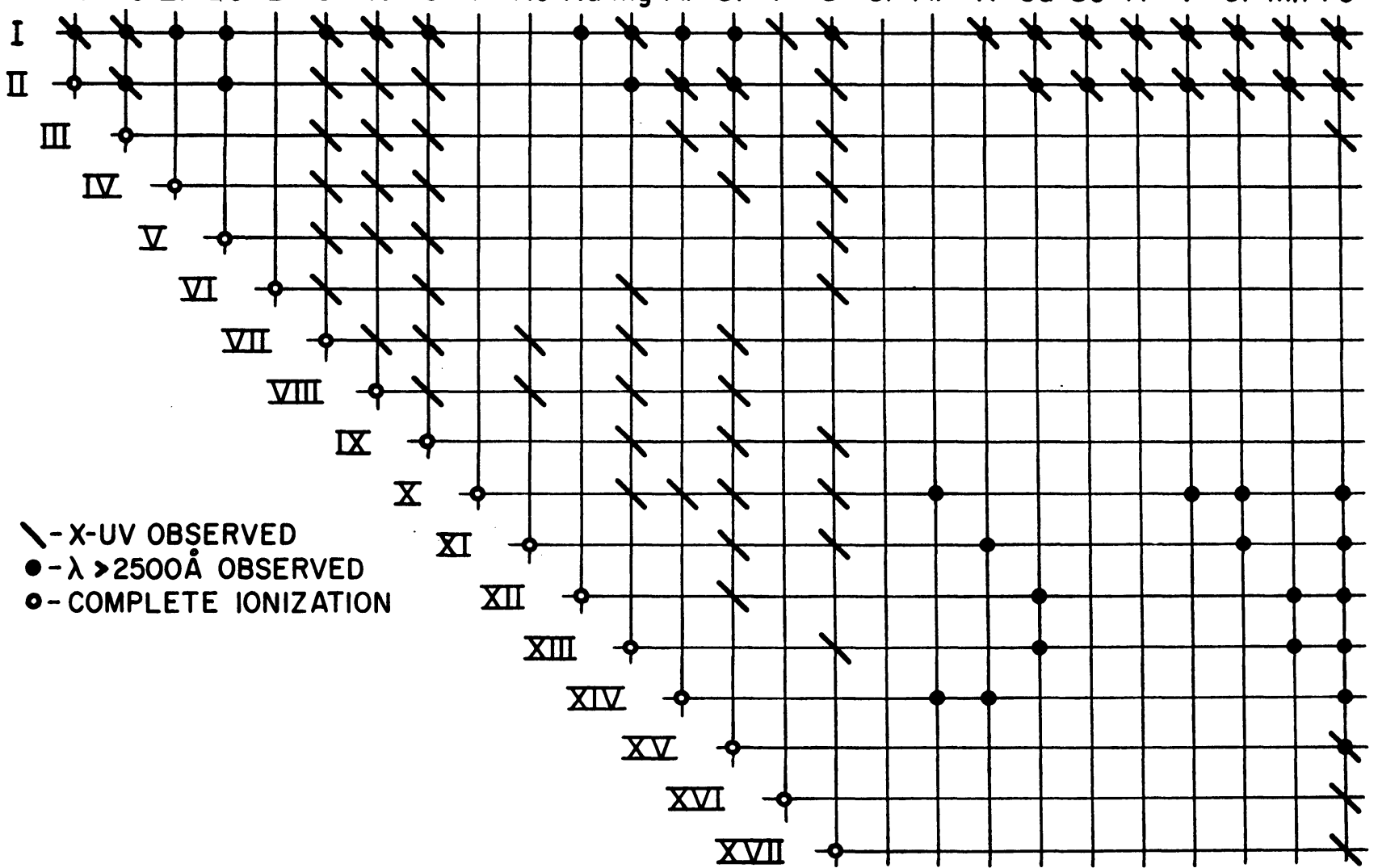

up to and including $\mathrm{O} \mathrm{V}$; the ionization potential to ionize $\mathrm{O} \mathrm{V}$ and produce $\mathrm{O} \mathrm{VI}$ is more than $100 \mathrm{eV} ; 200 \mathrm{eV}$ will produce both $\mathrm{O} \mathrm{VI}$ and 0 VII but not $O$ VIII, which requires $739 \mathrm{eV}$. The wavy nature of the boundaries is not significant, since it reflects small differences in ionization potential of the order of a few volts when the value happens to be close to that for the particular contour.

It is seen that no extreme ultraviolet lines of elements whose abundance in the Sun is less than that of aluminium have been found. Looking at the various isoelectronic sequences, the lithium and beryllium sequences are quite well filled out, the gaps being associated with scarce elements. For the more complicated spectra, however, fewer ions have been detected. It is surprising that in the fluorine sequence no lines at all have been detected, and in the neon sequence none with the exception of Fe XVII ; one might expect $\mathrm{Ca} \mathrm{X}$, and indeed there is a possible line at $111 \AA$ in HINTEREGGER's spectrum, but it is not at all strong ; also expected would be Si V and Mg III ; the latter lies at $231.73 \AA$, a region filled with blends, but it is clear that the magnesium line, if present, must be faint.

It has been suggested by ZIRIN and DiETZ (1963) that since lines from ions requiring between 100 and $300 \mathrm{eV}$ for formation were very few and faint, the temperature rise with altitude in the chromosphere must be extremely steep, so that not enough ions were present to produce lines of intensity great enough to detect. This conclusion now seems open to question. From Table III it is seen that lines have been recorded from a number of ions requiring between 100 and $300 \mathrm{eV} ; 0 \mathrm{VI}$, Ne VII, Ne VIII, Mg VI, VII, VIII, and IX and Si VII and VIII. There seems to be little evidence of any preferential distribution.

\section{SPECTROHELIOGRAMS}

Not long after the first extreme ultraviolet solar spectra were obtained from rockets, attempts were made to photograph the Sun's disc in the light of 
the Lyman-alpha line of hydrogen. The first photograph was obtained by Mercure, Miller, RENSE, and STUART (1956). Although the image was small and of low density and was confused with instrumental stray light, it was clear that Lyman-alpha was emitted with great intensity over plage regions as recorded from the ground in Ca K. Using a double-dispersion normalincidence system on March 19, 1959, Purcell, PACKER, and Tousey (1959) obtained a Lymanalpha spectroheliogram showing spatial detail to 1 minute of arc or better. In Lyman-alpha the plage regions resembled those observed in $\mathrm{Ca} \mathbf{K}$, but exhibited greater contrast and less detail.

It has proved to be difficult to obtain spectroheliograms of the Sun in emission lines other than Lyman-alpha. In most regions the lines are packed close together and cannot be separated without the use of a true spectroheliograph with moving entrance and exit slits. Spectroheliograms of a portion of the Sun, however, were obtained on May 10, 1963 by GarretT, PURCELL, and TOUSEY (1963); (TOUSEY, 1964). A strip across the Sun 7 minutes in width, was photographed in $H I$, Ly $\alpha$ and $\beta, O$ VI, 1031.91, 1037.61 $\AA$, and C III, 977.026 $\AA$. The principal conclusion from these spectroheliograms was that pronounced limb brightening occurs with the O VI lines and is qualitatively of the type to be expected for radiation arising from an optically thin shell of emitting gas located in the upper chromosphere. For the other lines there was little limb brightening. It was also apparent that the $O \mathrm{VI}$ lines were enhanced to a greater extent than the other lines in regions near the limb where the $\mathrm{Fe}$ XIV, $5303 \AA$ line was recorded as present.

Spectroheliograms in the grazing-incidence wavelength region cannot be obtained with double-dispersion normal-incidence instruments because of the extremely low reflectance of the gratings, and with grazing-incidence instruments the great amount of astigmatism makes it impossible to produce images of the Sun. Purcell, GaRRETT, and Tousey (1964), however, were successful in obtaining images with a simple normal-incidence spectrograph by placing an unbacked film of aluminum directly in front of the photographic film to remove the stray light. Sunlight was allowed to fall directly on a concave diffraction grating of $40-\mathrm{cm}$ radius of curvature and ruled with 2400 lines $/ \mathrm{mm}$. The grating was arranged so that $\mathrm{He}$ II, $304 \AA$, the center of the desired spectral region, was diffracted along the normal to the grating. This is the condition for the formation of a stigmatic image. Actually, the image quality was excellent for a considerable wavelength range on either side of the grating normal.

The first flight of this instrument on May 10, 1963 was successful and spectro-heliograms from $180 \AA$ to $350 \AA$ were obtained (TouSEY, 1964). Spectroheliograms obtained on September 20, 1963 with the same instrument, but readjusted to cover the range $280 \AA$ to $640 \AA$, are shown in Figure 10 and 11. The entire exposure is shown in Figure 10, printed in three sections so as to bring out as much detail as possible. Approximately one-half of the film in the central range was fogged by stray light coming through holes in the aluminum filter. In Figure 11 the end portions of this exposure-are shown enlarged by a factor of two and " dodged" in printing so as to bring up the greatest possible detail. Also shown is the Fraunhofer Institute map for the same day. The key below the spectroheliogram gives the locations of the most conspicuous active regions in the various emission lines. There were present on the Sun a strong plage surrounding a sunspot located close to the center, and two others near the east limb, as well as several fainter regions of enhanced activity.

The active region at the center gave rise to a number of flares; one of Class 2, was observed by Moreton (1964) to go through an explosive phase at $23 \mathrm{~h} 58 \mathrm{~m}$. The rocket flight, however took place at $15 \mathrm{~h} 45 \mathrm{~m}$, when no flare was reported. The green line was intense at the east limb from $-10^{\circ}$ to $+40^{\circ}$ latitude with maximum intensity at $+10^{\circ}$. Over the west $\operatorname{limb}$ there was a broad region of enhanced green line activity extending nearly to the South Pole.

Two images of the Sun were obtained in $\mathrm{He}$ II, $303.78 \AA$, one in first order and the other in second order. They are approximately alike, and apparent differences are caused by the overlapping of other solar images. For example, in the first order image the prominence-like object at the left is actually the central active region of the Fe XV image. The spatial resolving power of the instrument was approximately 1 arc minute, as is confirmed by the sharpness of the edge of the solar images. The detail in the Sun's surface however, is considerably less than 1 minute. The active regions seen in $\mathrm{He}$ II, $303.78 \AA$ correlate well with those recorded in $\mathrm{Ca} K$, as was the case in 1959 with $H$ I Ly $\alpha$, and contrast between plage regions and quiet background is greater than in Ca K, One of the most conspicuous effects. 
however, is the enhancement at the limb. This follows rather closely the green line activity as recorded around the limb. Where no green line activity was recorded, there is no enhancement. This is especially true in the region of the north pole.

An image of a similar type can be seen in Mg IX, 368.07 $\AA$; looking at the left hand half, which is the portion not obscured by fog, there is a thin bright ring along the east limb, which extends over a much greater range than the $5303 \AA$ line activity as recorded from the ground. The active regions and radiation from the disc in general are also present. Also visible in Figure 10 is $\mathrm{He} \mathrm{I}, 584.33 \AA$, but here there is confusion from fog. The central plage can be seen as well as the stronger of the two plages near the east limb. Faintly present also is $\mathrm{O}, 629.73 \AA$, largely from the disc, but with its central and east limb plages falling on the limb of the second order $\mathrm{He}$ II, $303.78 \AA$ line image.

The coronal lines $\mathrm{Fe}$ XVI, 335.3, 360.8 $\AA$ are of particular interest, because they appear with extreme intensity in the active regions, but do not show at all in the disc as a whole. This was also true of $\mathrm{Fe} \mathrm{XV}, 284.1 \AA$, as photographed on May 10, 1963. It might be expected that the Sun's limb would be bright in Fe XVI following the region of enhanced Fe XIV activity as was the case with Mg IX. However, this is not the case and no emission of $\mathrm{Fe} X V I$ can be seen except from plage regions. This is further evidence that Fe XVI and XV are emitted under different conditions than $\mathrm{Fe} \mathrm{XIV}$.

In Figures 3 and 4 it can be seen that the spectrum formed from the entire solar disc includes the three intense second orders of 171.06, 174.54, and 177.24 $\AA$, as well as the second order of $180.41 \AA$. The latter coincides with Fe XVI, $360.8 \AA$ and masks it completely, while the three former lines lie between the two lines of Fe XVI. In Figures 10 and 11, however, the situation is entirely different. Here the three second order lines which should appear between the two lines of Fe XVI are completely absent in the central active region, but background emission associated with images of the solar disc as a whole covers the region. The situation appears to be the same for the line $180.4 \AA$; its second order forms background radiation, but does not contribute appreciably to the Fe XVI, $360.8 \AA$ active regions. It is concluded that the lines of both Fe XVI and Fe XV show in the active regions but not in the disc as a whole, whereas the intense lines from $171.06 \AA$ to $180.41 \AA$ are emitted principally from the disc and with relatively little enhancement in the active regions. It is not possible to derive precise conclusions concerning intensities however, since the images are so small that it is difficult to measure densities accurately, and because the relative spectral efficiency of the spectroheliograph and the grazingincidence spectrograph have not been determined.

In Figure 10, streaks can be seen in the direction of dispersion. These are associated with the two active regions on the limb, and to a less extent with the central active region. The streak associated with the more intense of the two east limb plages runs across the entire length of the spectrum, and can be followed all the way through the fogged region, $400 \AA$ to $550 \AA$. This streak shows no suggestion of enhancement at emission lines other than those noted on the figure. It is interpreted as continuum emission associated with the plage, and is believed to be largely the second order of a continuum extending from $171 \AA$ to about $300 \AA$. That the continuum is not first order is concluded from two observations ; first, it becomes weak and practically disappears at $\lambda<340 \AA$, the second order position corresponding to the cut-off of the aluminum filter $170 \AA$; second, it extends with little change in intensity all the way to $600 \AA$, although the aluminum filter transmits very poorly in the range $\lambda>400 \AA$. This continuum was present in the first spectroheliograms of May 10, 1963, but was less clearly distinguishable from emission lines, because of the reduced dispersion in the first order.

Continuum radiation in the extreme ultraviolet is produced by both free-free and free-bound transitions. Calculations of the radiation expected from the quiet Sun in the X-ray range have been made by ELWERT (1961). There are many possibilities for the production of free-bound continua when electrons are recaptured by the various highly stripped atoms that are present in the corona and in plage regions. In some cases recapture will take place to the ground level, but in other cases, recapture will go directly to some excited level. The result could very well be a smooth continuum showing no structure at all, associated with plage regions where the density of highly stripped atoms is unusually high.

The conclusions reached from the photographic spectroheliograms tie in closely with data obtained on the variation of the solar spectrum with time, as recorded by NEUPERT, BHHRING, and LINDSAY (1964) from OSO-I. Observing the 
R. TOUSEY, W. F. AUSTIN, J. D. PURCELL ANL R. G. WIDING

solar spectrum from $170 \AA$ to $340 \AA$ over a time interval corresponding to about three solar rotations, they found that the emission lines $\mathrm{Fe} X V$, $284.1 \AA$ and Fe XVI, 335.3 $\AA$ varied by a factor of about four from minimum to maximum. He II, 303.78 $\AA$, on the other hand, was enhanced by a factor of only $33 \%$ during this period. They concluded that the emission of the coronal lines of $\mathrm{Fe} \mathrm{XV}$ and XVI is relatively much more intense in active regions than is the case for $\mathrm{He} I I$, $303.78 \AA$, which is of course apparent from Figure 10. During the course of the OSO-I observations, however, the emission in $\mathrm{Fe} X \mathrm{XV}$ and XVI never dropped to zero. From an analysis of the curves showing the variation with time of these emissions, NEUPERT (1964) concluded that the $\mathrm{Fe} X V$ and XVI intensity associated with a plage area is approximately 150 to 200 times greater than that of an equivalent area of the quiet Sun. This is not in disagreement with the spectroheliograms, because an intensity level only $1 \%$ as great as in the active regions would have been below the photographic threshold.

The time variation of various other emission lines has been studied by NEUPERT (1964). It was found that the emission lines 171.1, 174.5, and $177.2 \AA$ are among those which vary least with solar activity. During the period studied the ratios between maximum and minimum were only 1.2. This also is in agreement with the spectroheliograms, where emission in these lines was detected over the entire disc but not in the active regions. This suggests that the origin of these lines, which have also been observed in Zeta and the iron-loaded $\theta$-pinch, is probably a low stage of ionization, perhaps Fe IX, rather than Fe XIII. The line $180.4 \AA$ was found to vary slightly more, but was not in the class with Fe XVI, an observation which is also in agreement with the spectroheliograms.

It is obvious that a great deal can be learned from the study of the Sun by spectroheliographic methods. To accomplish this it will be necessary to construct larger, higher-resolving instruments and to fly them in orbiting vehicles. The Advanced Orbiting Solar Observatory (AOSO) being developed by NASA offers the possibility of accomplishing this, since a pointing accuracy of 1 arc second is expected to be attained, and sufficient space is available for large optical systems with great light gathering power. In the meantime, much more can be done from rockets and small orbiting observatories such as OSO.

\section{ACKNOWLEDGMENTs}

We are grateful to Pr B. EDLEN for many discussions and suggestions concerning the identification of extreme ultraviolet lines in the solar spectrum.

Manuscrit reçu le $1^{\mathrm{er}}$ mars 1965.

\section{REFERENCES}

Austin W. E., Purcell J. D. and Tousey R., 1962, Ast. J., 67, 110.

Austin W. E., Purcell J. D. and Tousey R., 1962, J. Opt. Soc. Am., 52, 597.

Behring W. E., Neupert W. M. and Lindsay J. C., 1963, Space Research, III (Ed. by W. Priester), North-Holland Publ. Co., Amsterdam, p. 814.

Blake R. L., Chubb T. A., Frimdman H. and UnziCKER A. E., 1964, Science, 146, 1037.

Detwiler C. R., Purcell J. D. and Tousey R., 1961, Mém. Soc. Roy. Sc. Liège, 50, Ser., 4, 254.

Detwiler C. R., GarretT D. L., Purcell J. D. and Tousex R., 1961, Ann. Geophys., 17, 9.

DE JAGER C., 1963, B. A. N., 17, 49.

EdLEN B., 1951, Arkiv. Fys., 4, 441.

Edeter B., 1962, Space Age Astronomy, Ed. by A. J. Deutsch and W. B. KLEMPERER, Academic Press, New York, p. 194.

Elton R. C., Kolb A. C., Austin W. E., Tousey R. and Widing K. G., 1964, Ap. J., 140, p. 389.

Elwert G., 1961, J. Geophys. Res., 66, 391.
Fawoett B. C., Gabriel A. H., Griffin W. G. Jones B. B. and WILson R., 1963, Nature, 200, 1303.

Fawcett B. C. and Gabriel A. H., 1964, Ap. $J$. (to be published).

Garstang R. H., 1962, Ann. d'Astro., 25, 109.

Goldberg L., Müller E. A. and Aller L. H., 1960, $A p . J .$, Suppl. $5,1$.

Heroux L., 1964, Proc. Phys. Soc., 83, 121.

HiNTEREGGer H. E., 1960, Ap. J., 132, 801.

Hinteregaer H. E., 1961, J. Geophys. Res., 66, 2367.

Hinteregger H. E., Hall L. A. and Schweitzer W., 1964, Ap. J., 140, 319.

HinteregGer H. E., HaLl L. A. and Schmtede G., 1964, Space Research, V.

House L. L. and SawYer G. A., 1964, Ap. J., 139, 775.

Jefferies J. T. and Thomas R. N., 1959, $A p . J ., 129$, 401.

Jafferies J. T. and Thomas R. N., 1960, $A p$. J., 131,695 . 

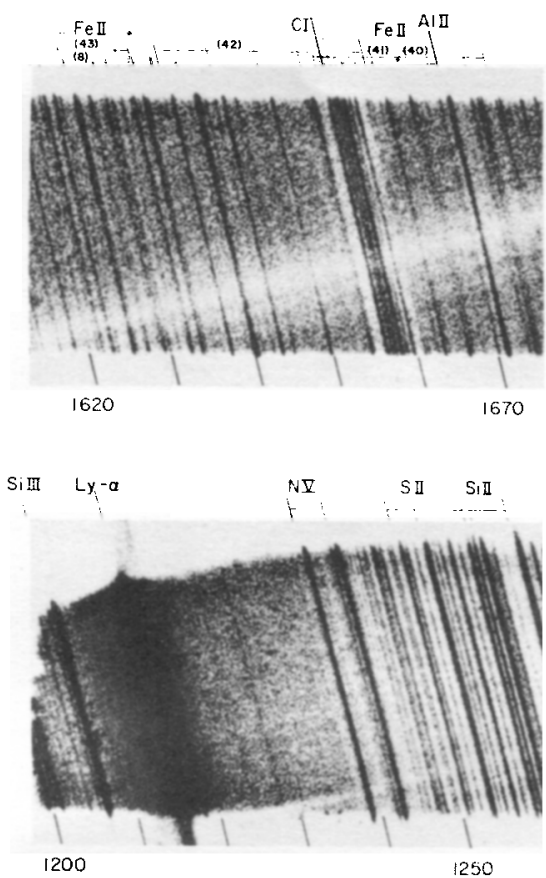

Fe I

SiI (7)

CI

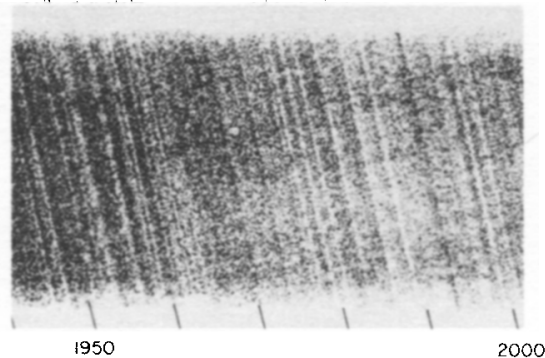

Sil( $\mathrm{SI}$

CD

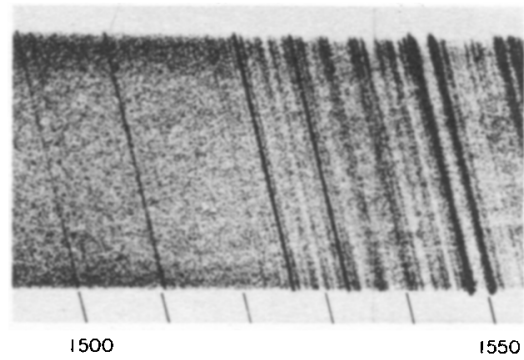

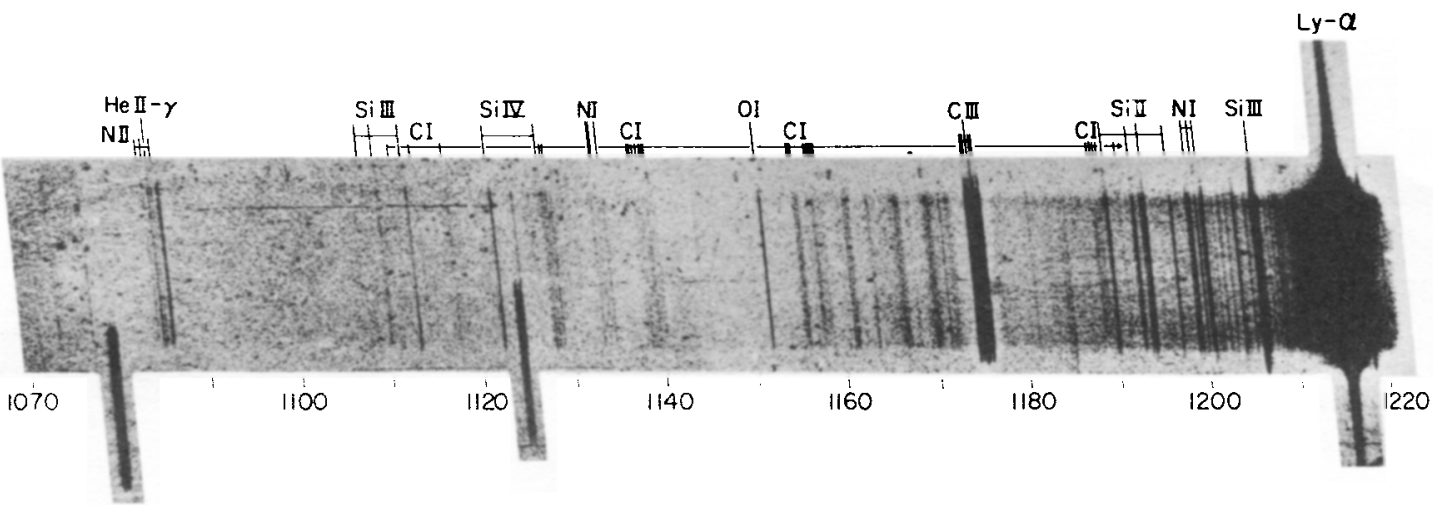
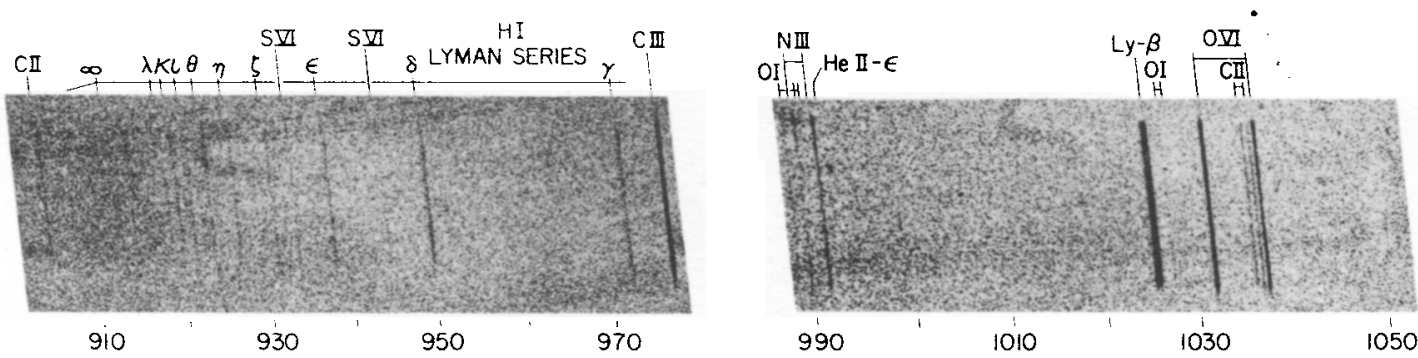

2

Fig. 1- Four sections of the spectrum obtained on August 22, 1962 with a double-dispersion grating spectrograph. Fig. 2 - The principal portions of a spectrum obtained on August 22, 1962 with a double-dispersion grating spectrograph. 

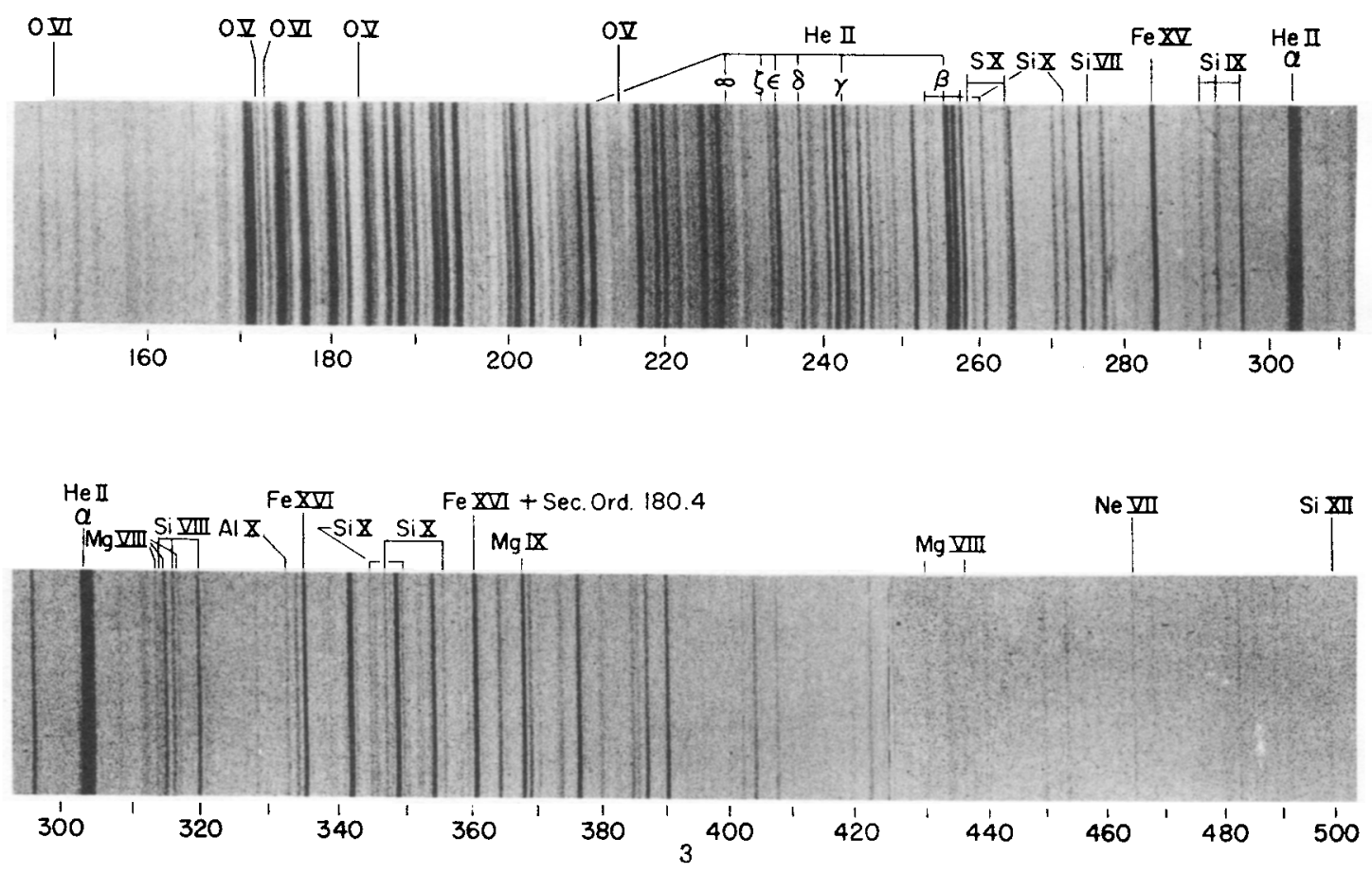

NRL

SEPT. 20,1963

NRL

MAY 10, 1963

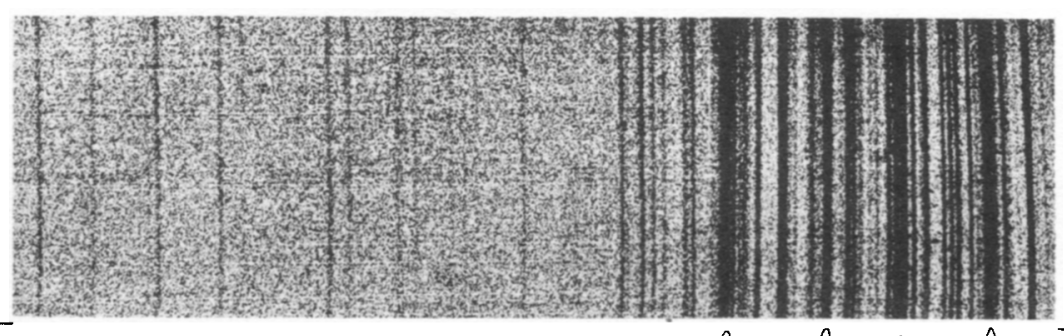

5000

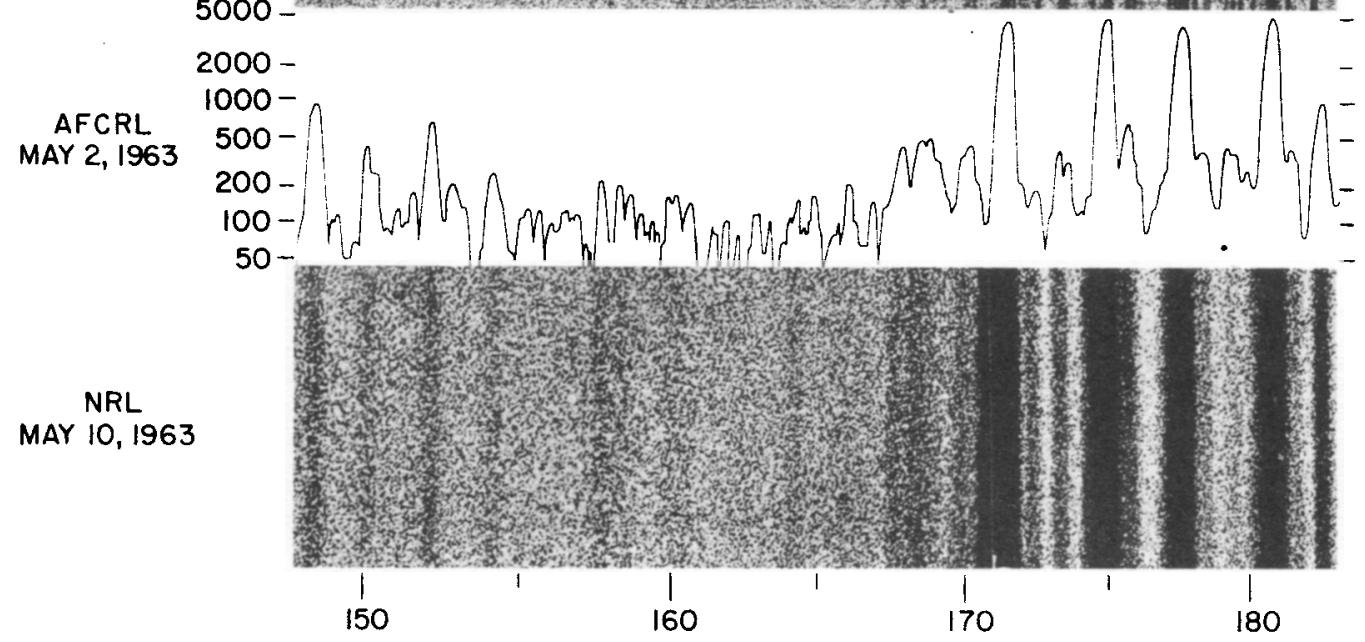

4

Fig. 3 - The solar spectrum, photographed on May 10, 1963 with a grazing incidence spectrograph. Fig. 4 - Spectra obtained by the U.S. Naval Research Laboratory, on May 10, 1963 with a 600-line/mm grating, and on September 20, 1963 with a 2400-line/mm grating, and by the Air Force Cambridge Research Laboratories on May 2, 1963 with a photoelectrically scanned monochromator. The vertical scale is counts per second recorded by the monochromator. 


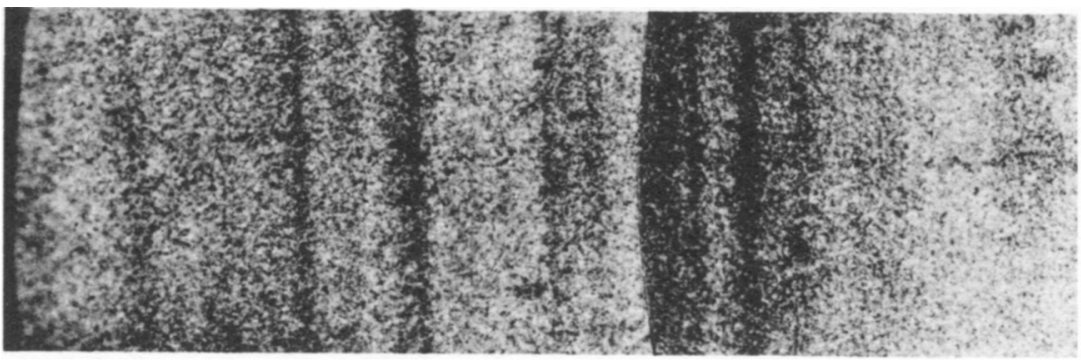

SEPT. 20, 1963

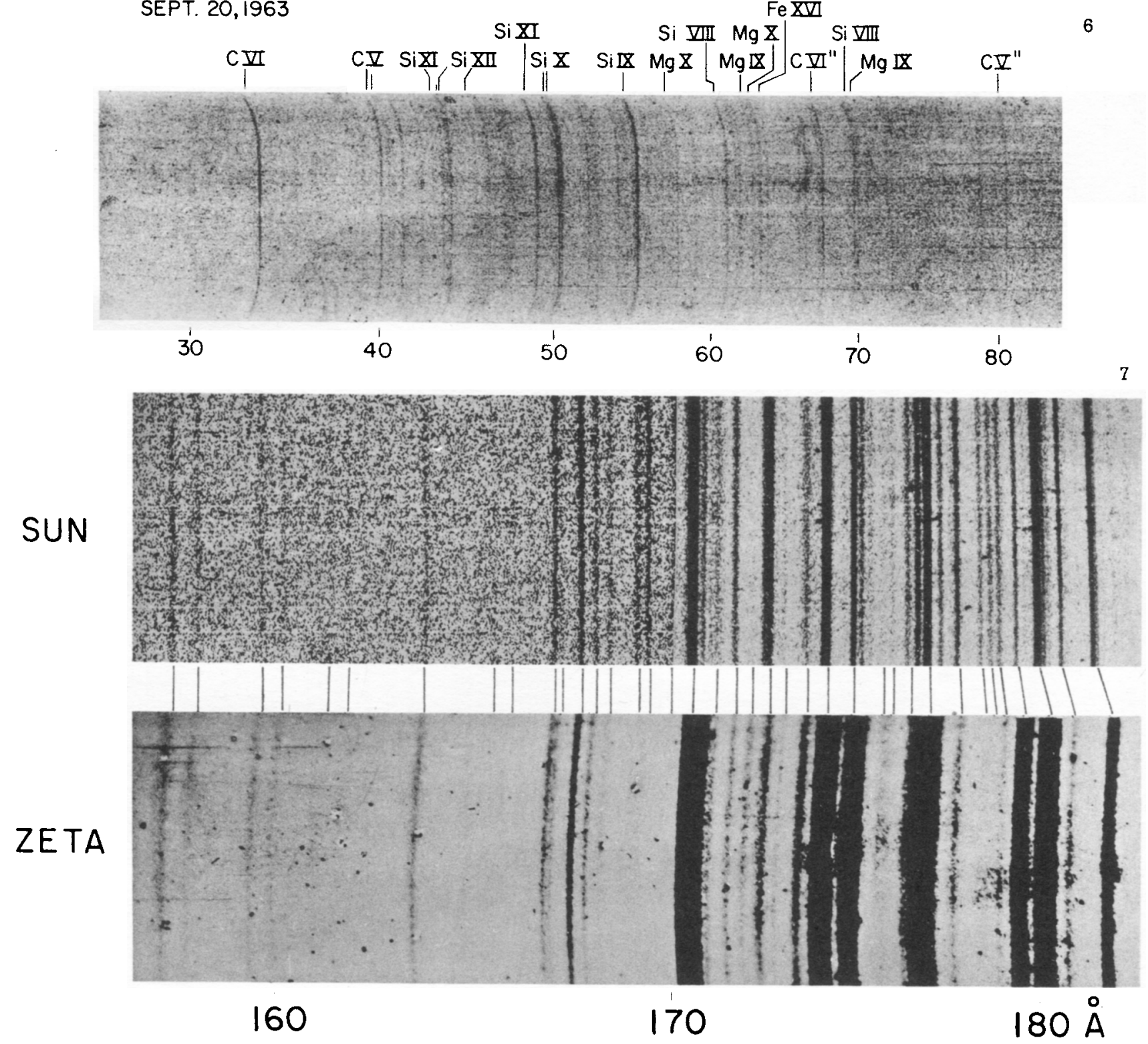

Fig. 6 - The soft x-ray spectrum of the sun, photographed by the U.S. Naval Research Laboratory on May 10 , 1963 with a 600-line/mm grating, and on September 20, 1963 with a 2400-line/mm grating. Fig. 1 - The solar spectrum photographed by the U. S. Naval Research Laboratory on September 20, 1963 compared with the spectrum of Zeta, photographed by the Culham Laboratory of the United Kingdom Atomic Energy Authority. 
Fig. 8 - A section of the U.S. Naval Research Laboratory Spectrum of September 20, 1963, showing lines present in Zeta, one of which nearly or completely masks H-alpha of C VI.

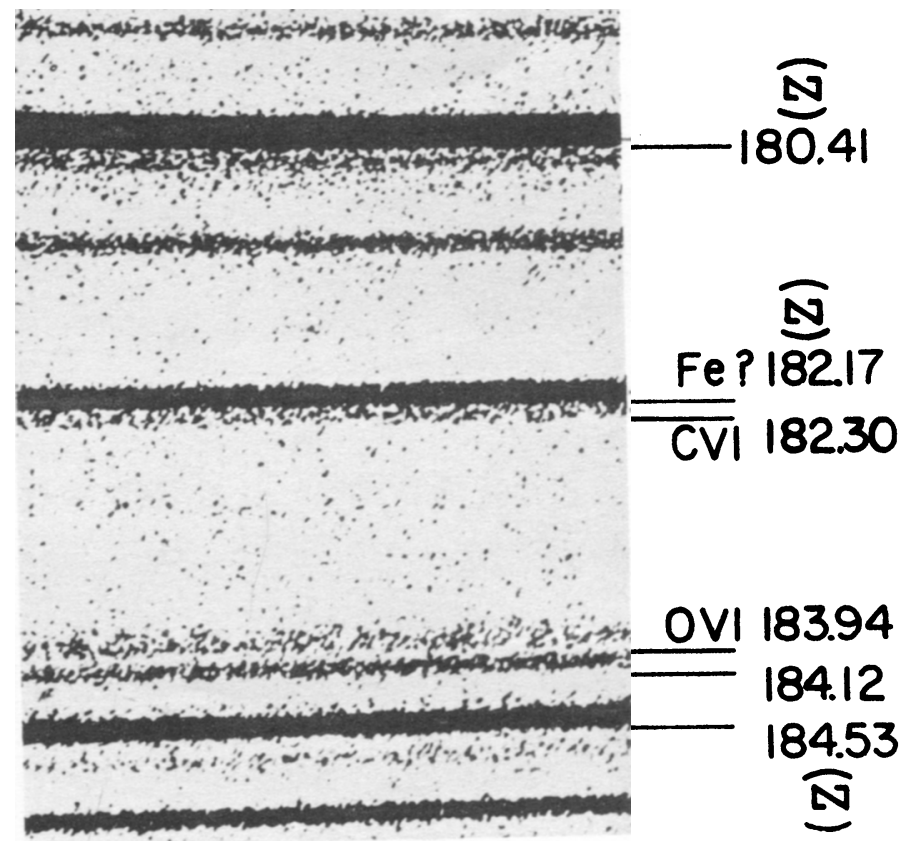

Fe XIV

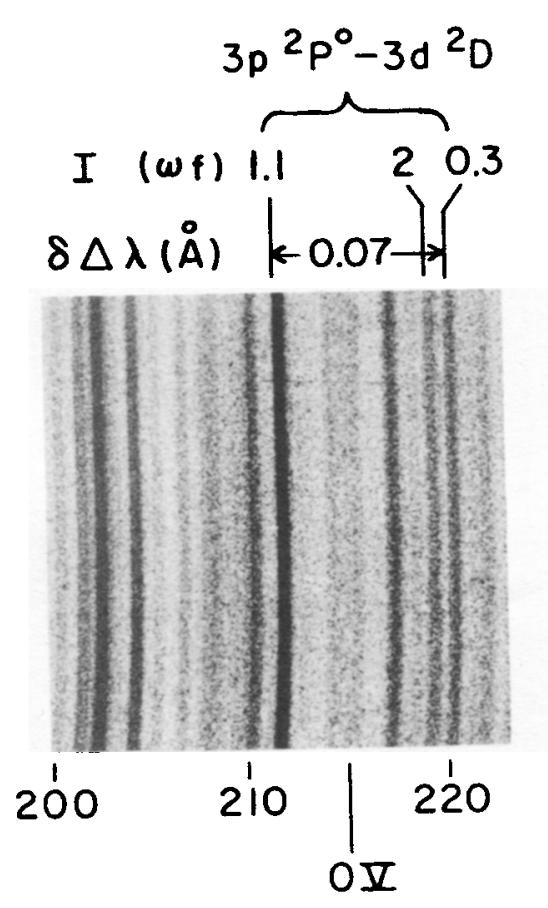

Fig. 9 - The parts of the U. S. Naval Research Laboratory spectrum of May 10, 1963 where the resonance lines of Fe XIV should appear. Values of (1) are from Garstang (1962). isi indicates the difference between observed and calculated separations between the pairs of lines which are most nearly correct for Fe XIV. 


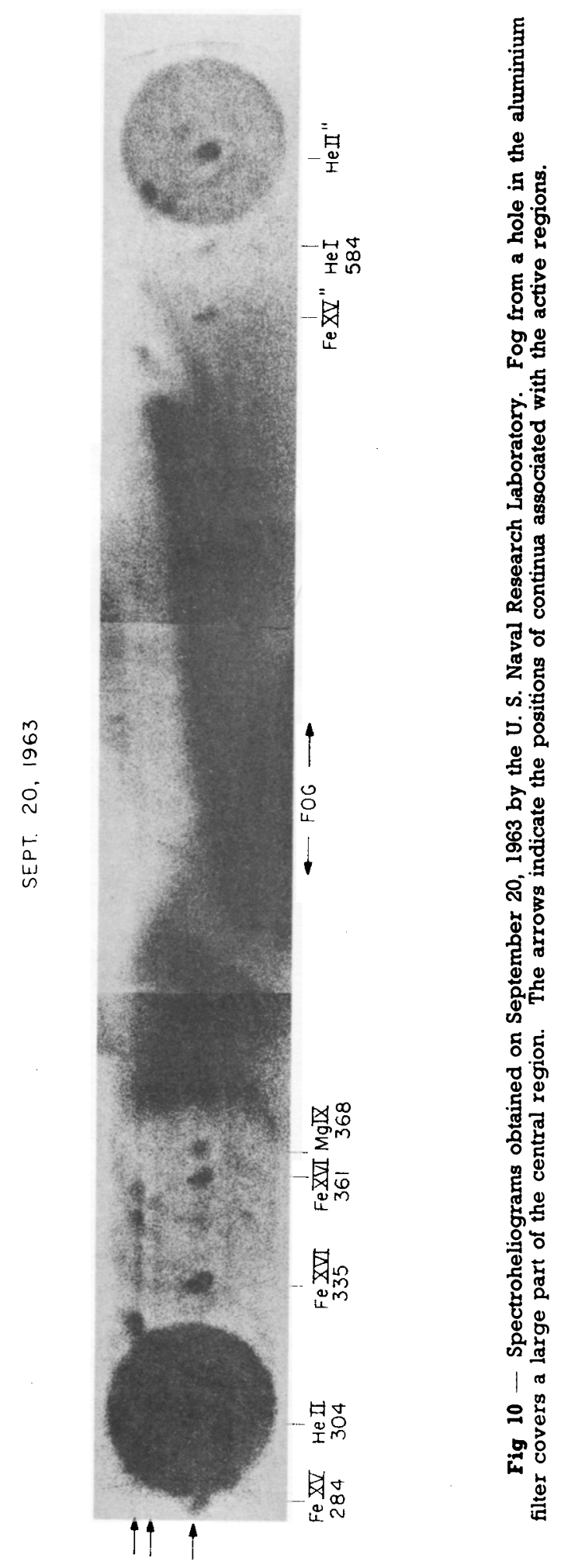

TOUSEY et Al. I-1 


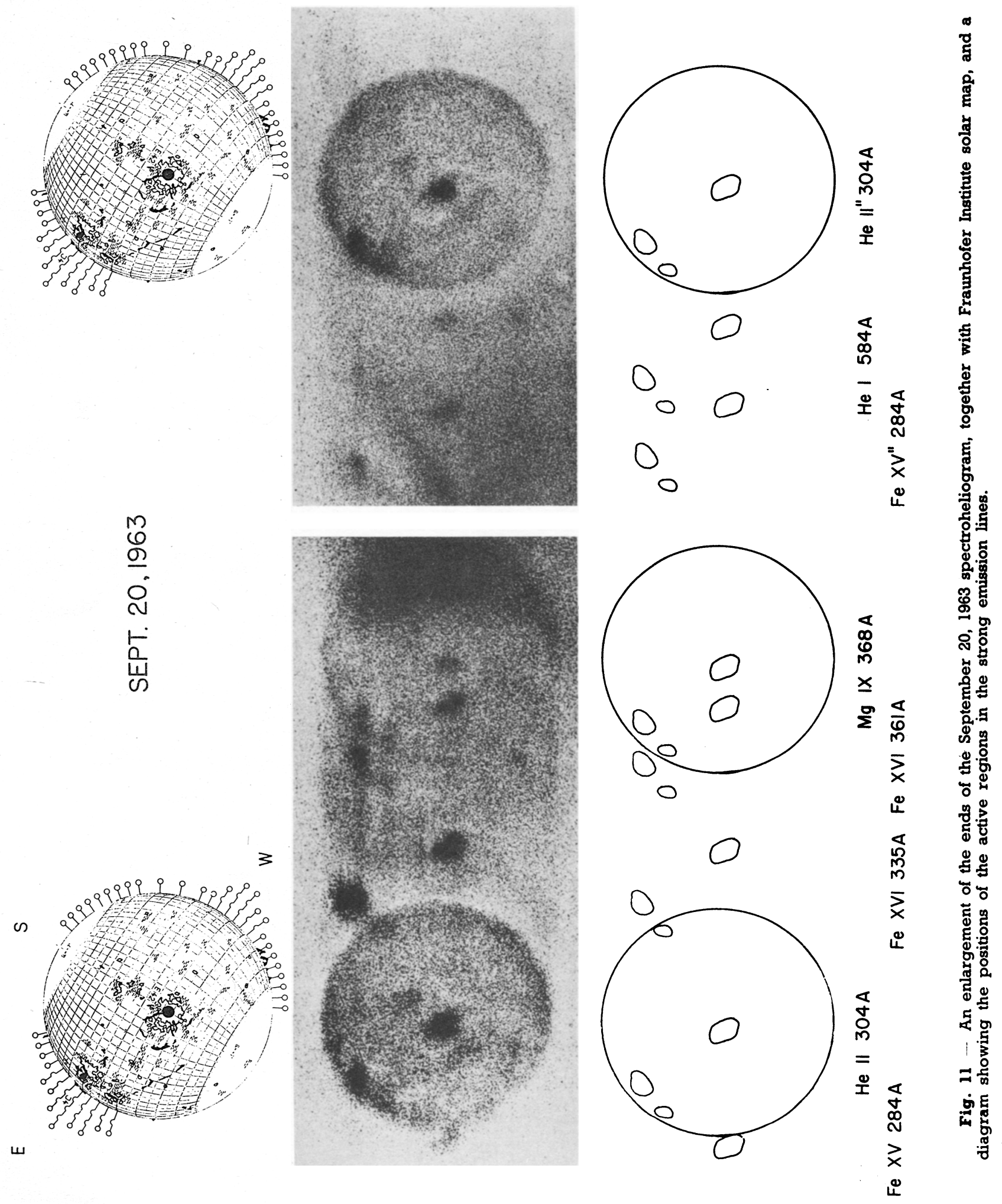


Moone C. E., 1950, “ An Ultraviolet Multiplet Table ”, Circ. Nat. Bur. Standards No 488, U. S. Govt. Printing Office, Washington, D. C.

Moreton G. E., 1964, Astr. J., 69, 145.

Morton D. C. and Widing K. G., 1961, Ap. J., 133, 596.

Neupert W. M. and Smith E. v. P., 1964, Astr. J., $69,554$.

Neupert W. M., Behring W. E. and Lindsay J. C., 1964, Space Res., IV, Ed. P. MuLwER, NorthHolland Publ. Co., Amsterdam, p. 719.

Ogawa M. and CaIrns R. B., 1964, Planet. Space. Sci., $12,656$.

Purgell J. D., Pagker D. M. and Tousey R., 1959, Nature, 184, 8.

Purcell J. D. and Tousey R., 1960, J. Geophys., $65,370$.

Purcell J. D., Garrett D. L. and Tousex R., 1963,
Space Res. III, Ed. W. Priester, North-Holland Publishing Co., Amsterdam, p. 781.

Purgell J. D., Garrett D. L. and Tousey R., 1964, Astr. J., 69, 147.

Rense W. A., 1953, Phys. Rev., 91, 299.

Tousex R., 1962, Space Age Astronomy, Ed. by A. J. Deutsoh and W. B. KLemperer, Academic Press, New York, p. 104.

Tousey R., Purgell J. D., Austin W. E., Garkett D. L. and Widing K. G., 1963, Space Research, IV, p. 703.

Tousey R., 1963, Space Sci. Rev., 2, 3.

Tousey R., 1964, Quart. J. of the Roy. Astr. Soc., 5, 123.

VioletT T. and Rense W. A., 1959, Ap. J., 130, 954.

Worley R. E., 1943, Phys. Rev., 64, 207.

ZirIN H. and DreTz R. D., 1963, Ap. J., 138, 664.

ZIRIN H., 1964, Ap. J., 140, 1332.

\section{Discussion}

J. Rosor. - There is a gap at Fe in your table : Dr. MranotTe has observed Fe XII $3010 \AA$ during the total eclipse of 1958.

M. MigeotTE. - Lors de l'éclipse solaire du 30 juin 1954, en collaboration avec M. B. Rosen (Ciel et Terre, 71, 288, 1955), nous avons effectivement observé une raie attribuée à Fe XII. Cette identification nous a d'ailleurs été suggérée par E. EDLÉn. Nous espérons effectuer de nouvelles observations concernant cette raie lors de l'éclipse solaire de mai 1965.

P. C. Fisher. - Your present identification of the line $182,2 \AA$ is that it is due to Fe, rather than C VI. Is the $\theta$ pinch so clean that no $C$ VI line exists to cause confusion, or does the line become intense when the pinch is spiked with $\mathrm{Fe}$ ?

R. Tousey. - In the N. R. L. $\theta$ pinch, R. C. Elton and A. C. KoLB introduced $\mathrm{Fe}$ in pure metal form, rather than as iron carbonyl. No lines of Carbon were present, and the 182,2 $\AA$ line appeared only when $\mathrm{Fe}$ was added.

R. WILson. - The line at 182,16 $\AA$, observed in the Zeta spectrum, is not the Balmer $\alpha$ line of C VI since it can be observed very strongly under conditions where the Lyman $\alpha$ line of C VI is absent. Dr. TousEY's talk indicates that this is also true in the Sun.

The line is one of the intense unknown system between 170 and $210 \AA$ which has been proven by GaBRIEL and FAwoetT of Culham Laboratory to be due to the element Fe.

L. Goldmbra. - You stated that wavelengths can be measured with an accuracy of $0,02 \AA$ near $1200 \AA$. Have you compared such measurements with laboratory wavelengths and, if so, how close is the agreement? Lines formed at different heights in the chromosphere-corona may exhibit differential Doppler shifts as a result of velocity gradients.

R. TousEY. - We have looked for effects of this sort, but have not found any as yet. Comparison of the lines C II 1037,017 - 1036,330 $\AA$ and $O$ VI $1031,912-1037,613 \AA$ seemed to offer the best poss1bility, since C II is low chromospheric and $\mathrm{O}$ VI high chromospheric or coronal. The observed separations are in agreement with the separations calculated from laboratory wavelengths to within $0,02 \AA$, from place

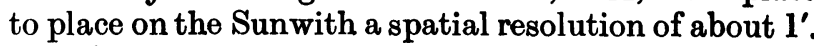
The C II lines do not change greatly in intensity and width across the Sun. The O VI lines become more intense and broader toward the limb but the broadening is symmetrical.

M. J. Seaton. - In discussing relative intensities of UV Fe XIV lines, do you consider only lines from a common upper level ? One could also consider relative intensities of line belonging to different upper levels.

R. Tousey. - We considered the relative intensities of the lines from both upper levels as well as to both lower levels, using the oscillator strengths computed by R. H. Garstang. The only multiplet which did not exhibit reversed or at least quite wrong relative intensities was $3 s^{2} 3 p^{2} \mathrm{P}^{0}-3 s 3 p^{2}{ }^{2} \mathrm{~S}$, which has only two lines.

Mrs. E. V. P. Smith. - R. Stockhansen has made calculations based on Garstang's f-values and the Seaton-Van Regemorter formulation to find the relative line strengths of XUV Fe XIV lines. The results differ considerably from the observed values. This discrepancy can perhaps be attributed to a form of self absorption.

L. GoLdBera. - The resolving power of the solar spectrum is still so low that blends may seriously alter the relative intensities of lines in multiplets.

Mrs. E. V. P. Smiтh. - Blends will, of course, still play a very important role. 